\title{
Heritable Phytohormone Profiles of Poplar Genotypes Vary in Resistance to a Galling Aphid
}

\author{
Mélanie J. A. Body, ${ }^{1,+}$ Matthew S. Zinkgraf, ${ }^{2}$ Thomas G. Whitham, ${ }^{2}$ Chung-Ho Lin, ${ }^{3}$ Ryan A. Richardson, ${ }^{1}$ \\ Heidi M. Appel, ${ }^{1}$ and Jack C. Schultz ${ }^{1}$ \\ ${ }^{1}$ Division of Plant Sciences, Christopher S. Bond Life Sciences Center, 1201 Rollins Street, University of Missouri, Columbia, \\ MO 65211, U.S.A.; ${ }^{2}$ Department of Biological Sciences and Merriam-Powell Center for Environmental Research, Northern \\ Arizona University, Flagstaff, AZ 86011, U.S.A.; and ${ }^{3}$ School of Natural Resources, 203 Anheuser-Busch Natural Resources \\ Building, 1111 Rollins Street, University of Missouri, Columbia, MO 65201, U.S.A.
}

Accepted 3 December 2018.

Insect galls are highly specialized structures arising from atypical development of plant tissue induced by insects. Galls provide the insect enhanced nutrition and protection against natural enemies and environmental stresses. Galls are essentially plant organs formed by an intimate biochemical interaction between the gall-inducing insect and its host plant. Because galls are plant organs, their development is likely to be governed by phytohormones involved in normal organogenesis. We characterized concentrations of both growth and defensive phytohormones in ungalled control leaves and galls induced by the aphid Pemphigus betae on narrowleaf cottonwood Populus angustifolia that differ genotypically in resistance to this insect. We found that susceptible trees differed from resistant trees in constitutive concentrations of both growth and defense phytohormones. Susceptible trees were characterized by significantly higher constitutive cytokinin concentrations in leaves, significantly greater ability of aphids to elicit cytokinin increases, and significantly lower constitutive defense phytohormone concentrations than observed in resistant trees. Phytohormone concentrations in both constitutive and induced

Current address for Mélanie J. A. Body, Heidi M. Appel, and Jack C. Schultz: Department of Environmental Sciences, Bowman-Oddy Laboratories, 2801 West Bancroft Street, University of Toledo, Toledo, OH 43606, U.S.A.

Current address for Matthew S. Zinkgraf: Biology Department, Western Washington University, 516 High Street, Bellingham, WA 98225, U.S.A.

Current address for Ryan A. Richardson: Department of Biology, 1 Brookings Drive, Washington University in Saint Louis, Saint Louis, MO 63130, U.S.A.

${ }^{\dagger}$ Corresponding author: M. J. A. Body; Melanie.Body@utoledo.edu

Funding: This project was supported in part by a grant to the University of Missouri from the Howard Hughes Medical Institute Precollege and Undergraduate Science Education Program grant 52006953 to J. C. Schultz and by National Science Foundation (NSF) Division of Integrative Organismal Systems grant 1256552 to J. C. Schultz and H. M. Appel. Long-term funding to maintain the common garden was provided by NSF Division of Environmental Biology FIBR grant 0425908, NSF MacroSystems grant 1340852, and NSF Division of Biological Infrastructure grant 1126840 for establishing the Southwest Experimental Garden Array to T. G. Whitham.

*The $\boldsymbol{e}$-Xtra logo stands for "electronic extra" and indicates that one supplementary table is published online. distributed under the CC BY-NC-ND 4.0 International license. responses in galled leaves exhibited high broad-sense heritability that, respectively, ranged from 0.39 to 0.93 and from 0.28 to 0.66 , suggesting that selection can act upon these traits and that they might vary across the landscape. Increased cytokinin concentrations may facilitate forming strong photosynthate sinks in the galls, a requirement for galling insect success. By characterizing for the first time the changes in $\mathbf{1 5}$ phytohormones belonging to five different classes, this study offers a better overview of the signaling alteration occurring in galls that has likely been important for their ecology and evolution.

Many insects manipulate the development of their host plants in a species-specific manner to generate galls - structures composed of atypical outgrowth of plant tissue within which the insect, its offspring, or both feed. These structures supply the gall-inducer with nutrients and protection against natural enemies and environmental stresses to enhance development, reproduction, and survival (Mani 1964; Price et al. 1987; Stone and Schönrogge 2003).

Insect gall development involves the active differentiation and growth of plant tissues with features of a novel organ, and galls increase in size via cell hypertrophy and tissue hyperplasia (Mani 1964; Shorthouse et al. 2005). Gall growth and its food content are supplied, in most cases, by forming a strong sink for photosynthates (Compson et al. 2011; Larson and Whitham 1991; Rehill and Schultz 2003). All these functions are normally controlled by phytohormones during plant growth and development. For this reason, many studies have measured concentrations of one or a few plant hormones in galls as compared with ungalled tissues (Bartlett and Connor 2014; Dorchin et al. 2009; Hori 1992; Mapes and Davies 2001a and b; Tanaka et al. 2013; Tooker and De Moraes 2009, 2011; Tooker and Helms 2014; Wood and Payne 1988). Hormone profiles may be altered by the plant in response to insect attack and may involve phytohormones produced by insects or their bacterial symbionts, or both (Body et al. 2013; Straka et al. 2010; Suzuki et al. 2014; Yamaguchi et al. 2012; Zhang et al. 2017).

Galling insects are herbivores and might, therefore, elicit hormonally regulated defense responses in their host plants. For example, jasmonates comprise a family of phytohormones that coordinate defense responses against necrotrophic pathogens and chewing herbivores (Erb et al. 2012; Pieterse et al. 2012; Thaler et al. 2012). Salicylic acid (SA) is a key phytohormone coordinating plant responses to infection by biotrophic pathogens, particularly by bacteria, and to fluid-feeding herbivores (Erb et al. 2012; Pieterse et al. 2012; Thaler et al. 2012). 
In this study, we attempted to determine whether altered phytohormone profiles are associated with genotypic resistance (Zinkgraf et al. 2016) to gall development. Our study system comprises galls formed at the base of the leaf blade of narrowleaf cottonwood Populus angustifolia by the aphid Pemphigus betae (Fig. 1) (Richardson et al. 2017). The success of the aphid Pemphigus betae on cottonwood genotypes varies from no or few galls to as many as 50,000 on an individual tree (Whitham 1983). Aphid survival rates range from 0 to $80 \%$ depending on tree genotype (Table 1) (Whitham 1989). Compson et al. (2011) have identified that the aphids' ability to develop a strong sink as one genetically based feature of cottonwoods influencing aphid success. Sink strength in plants is regulated by phytohormones, particularly cytokinins (CKs) (Roitsch and Ehneß 2000). Other gall characteristics, including size and shape as well as chemistry (e.g., sugar and condensed tannin contents [Larson and Whitham 1991; Bailey et al. 2006; Compson et al. 2011]) are likely regulated by phytohormones as well.

We hypothesize that plant resistance is likely to involve heritable phytohormone signaling pathways needed for gall growth, maintenance, and food supply, as well as plant defense. In this study, we quantified, for the first time, a suite of 15 phytohormones belonging to five different classes to obtain an overview of the alteration of phytohormone profile in galls. We characterized the relationship between tree genotypic resistance to galling and phytohormone concentrations in galls and ungalled leaves across five different tree genotypes, ranging from resistant to susceptible (Table 1) at three different dates. We examined differences in phytohormone profiles between galls and ungalled control leaves from each genotype to characterize how each genotype responds to galling. We also evaluated the hypothesis that constitutive and induced phytohormone profiles and response to galling could be related to the genetics of the host tree.

\section{RESULTS}

Variation in overall phytohormone signatures.

We first asked whether phytohormone concentrations as a whole ('profiles') in our sample population differed with tissue type (galls versus ungalled control leaves), tree genotype susceptibility, and sampling date. Phytohormone profiles differed significantly between galls and ungalled control leaves, among tree genotypes, and between collection dates (generalized linear models [GLM], three-way multivariate analysis of variance [MANOVA], $P \leq 0.001$ for each factor [Table 2]). We also found a significant interaction between factors (GLM, three-way MANOVA, $P \leq 0.001$ for tissuexsusceptibility, tissuexdate, and susceptibility $\times$ date [Table 2]) as well as for the interaction of these three factors (GLM, three-way MANOVA, $P \leq 0.001$ for tissuexsusceptibility $\times$ date [Table 2]).

\section{Variation in individual phytohormone concentrations.}

We then asked whether concentrations of individual phytohormones in galls and ungalled control leaves differed among

Table 1. Susceptibility index of five poplar genotypes to the galling aphid and sample sizes

\begin{tabular}{|c|c|c|c|}
\hline Genotype & $\begin{array}{l}\text { Susceptibility } \\
\text { index }\end{array}$ & Susceptibility $^{\mathbf{a}}$ & Number of bioreps \\
\hline 1008 & 0.00 & Resistant & $\begin{array}{l}4 \text { for leaves (pool of 5) } \\
4 \text { for galls (pool of 2-5) }\end{array}$ \\
\hline 996 & 0.07 & Resistant & $\begin{array}{l}6 \text { for leaves (pool of 5) } \\
7 \text { for galls (pool of 5) }\end{array}$ \\
\hline WC5 & 0.12 & Resistant & $\begin{array}{l}9 \text { for leaves (pool of 5) } \\
9 \text { for galls (pool of 5) }\end{array}$ \\
\hline 999 & 0.49 & Medium & $\begin{array}{l}10 \text { for leaves (pool of 5) } \\
9 \text { for galls (pool of } 5 \text { ) }\end{array}$ \\
\hline 1017 & 0.80 & Susceptible & $\begin{array}{l}9 \text { for leaves (pool of } 5 \text { ) } \\
9 \text { for galls (pool of } 5 \text { ) }\end{array}$ \\
\hline
\end{tabular}

${ }^{\text {a }}$ Based on gall success rate.

Table 2. Statistical analysis on the overall phytohormone signature ${ }^{\mathrm{a}}$

\begin{tabular}{lrrr}
\hline Factors & D.F. & $\boldsymbol{F}$ value & Pr $>\boldsymbol{F}$ \\
\hline Phytohormone signatures & & & \\
$\quad$ Tissue & 15,34 & 52.28 & $0.000 * * * *$ \\
Susceptibility & 60,148 & 11.35 & $0.000 * * * *$ \\
Date & 30,70 & 9.96 & $0.000 * * *$ \\
Tissuexsusceptibility & 60,148 & 6.70 & $0.000 * * *$ \\
Tissuexdate & 30,70 & 7.56 & $0.000 * * *$ \\
Susceptibility $\times$ date & 105,280 & 2.33 & $0.000 * * *$ \\
$\quad$ Tissuexsusceptibility $\times$ date & 105,280 & 3.04 & $0.000 * * *$ \\
Gall-induced phytohormone signature changes & & \\
Susceptibility & 60,44 & 12.89 & $0.000 * * *$ \\
Date & 30,18 & 17.44 & $0.000 * * *$ \\
Susceptibility $\times$ date & 105,98 & 4.69 & $0.000 * * *$ \\
\hline
\end{tabular}

${ }^{\mathrm{a}}$ D.F. $=$ degree of freedom, $\mathrm{F}$ value $=$ statistical value, and $\mathrm{PR}=P$ value.
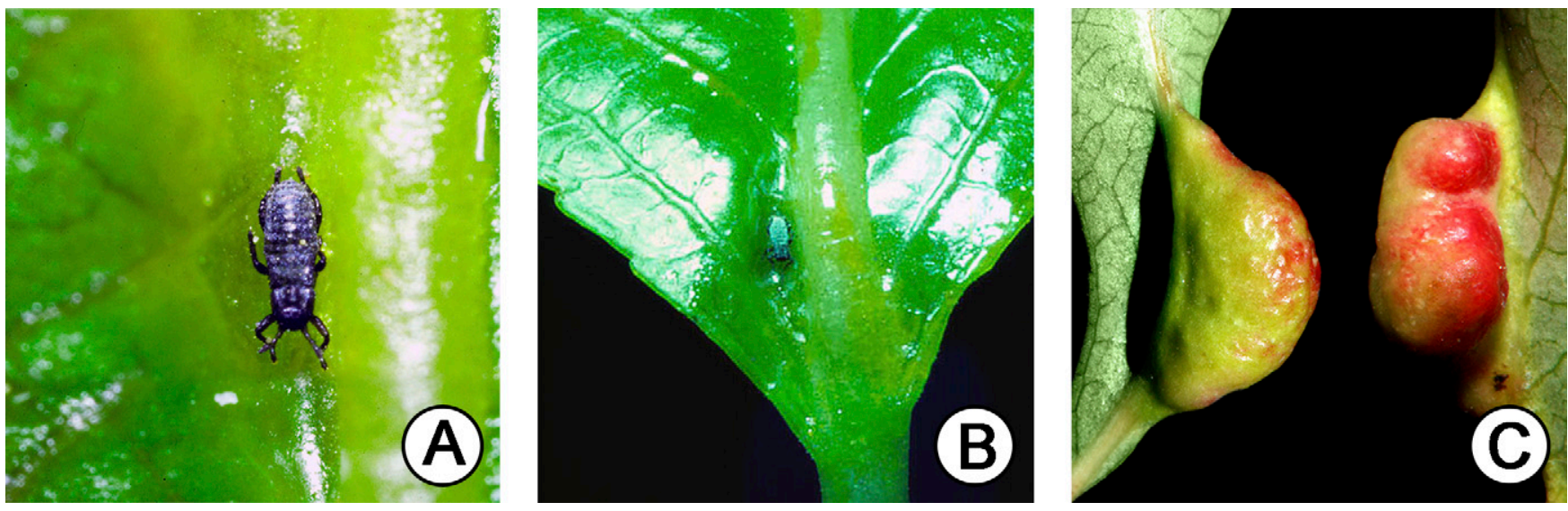

Fig. 1. Pemphigus betae aphid inducing a gall on Populus angustifolia leaves. A, Fundatrix aphid inducing a gall near the base of the midvein on the upper surface of a poplar leaf. B, Young gall forming near the base of the midvein on the upper leaf surface. The fundatrix (approximately $0.6 \mathrm{~mm}$ long) moves back and forth in the gall depression (approximately $3 \mathrm{~mm}$ long) adjacent to the midvein continually probing the leaf tissue with her stylet and, within about 3 days, is completely enclosed in gall tissue. C, Side view of fully developed galls that have formed on the underside of the leaf from the activity of the fundatrix on the upper leaf surface. Photo credits: A and B, Thomas G. Whitham; C, Heidi M. Appel. 
tree genotypes and sampling dates, using GLM procedures (Table 3 ) followed by posthoc Tukey's highly significant difference (HSD) tests when a significant effect was found.

Gibberellins (GAs). Constitutive concentrations of GA1, GA3, and GA4 in leaves were significantly greater on the two most-resistant tree genotypes (1008 and 996) (GLM procedure, Tukey's HSD posthoc test, $P \leq 0.05$ ), while leaf concentration of GA7 was greatest only on the most-resistant tree genotype 1008 (GLM procedure, Tukey's HSD posthoc test, $P \leq 0.05$ ). GA concentrations did not vary with sampling date in leaves (GLM procedure, $P=0.338$ for GA1, 0.538 for GA3, 0.691 for GA4, and 0.551 for GA7 [Fig. 2A]). In galls, concentrations of GA3 and GA4 were greatest in the mostresistant tree genotype (1008) (GLM procedure, Tukey's HSD posthoc test, $P \leq 0.05)$, concentration of GA1 was greater in the three most-resistant tree genotypes (1008, 996, and WC5) (GLM procedure, Tukey's HSD posthoc test, $P \leq$ 0.05). GA7 concentrations in galls did not differ among tree genotypes (GLM procedure, $P=0.297$ ). All GAs were significantly more concentrated in galls on the first sampling date (GLM procedure, Tukey's HSD posthoc test, $P \leq 0.05$ ), followed by declines for all the genotypes (Fig. 2A).
CKs. Concentrations of all four CKs in leaves were significantly greater on the most-susceptible tree genotype (1017) than on any other genotypes (GLM procedure, Tukey's HSD posthoc test, $P \leq 0.05)$. Concentrations of 6 -( $\Delta 2$-isopentenyl) adenine (iP), 6-( $\Delta 2$-isopentenyl) adenine riboside (iPR), and trans-zeatin (tZ) did not differ with sampling date in leaves (GLM procedure, $P=0.284$ for $\mathrm{iP}, 0.153$ for $\mathrm{iPR}$, and 0.210 for $\mathrm{tZ}$ ), while concentration of trans-zeatin riboside (tZR) in leaves was greatest on the first date (GLM procedure, Tukey's HSD posthoc test, $P \leq 0.05$ (Fig. 2B]). Concentrations of all CKs were significantly greater in galls on the mostsusceptible tree genotype (1017) (GLM procedure, Tukey's HSD posthoc test, $P \leq 0.05)$ and on the first sampling date (GLM procedure, Tukey's HSD posthoc test, $P \leq 0.05$ (Fig. 2B]).

Auxins (AUXs). Both indole 3 -acetic acid (IAA) and indole3-butanoic acid (IBA) were significantly more concentrated in leaves of the two most-resistant tree genotypes (1008 and 996) than in leaves of the other genotypes (GLM procedure, Tukey's HSD posthoc test, $P \leq 0.05)$. Concentrations of these two AUXs did not vary with sampling date in leaves (GLM procedure, $P=$ 0.431 for IAA, and 0.741 for IBA (Fig. 2C]). Both AUXs were

Table 3. Statistical analysis on individual phytohormones ${ }^{\mathrm{a}}$

\begin{tabular}{|c|c|c|c|c|c|c|c|}
\hline Phytohormone & Tissue & Susceptibility & Date & Tissuexsusceptibility & Tissuexdate & Susceptibility $\times$ date & Tissue $\times$ susceptibility $\times$ date \\
\hline \multicolumn{8}{|c|}{ Phytohormone concentrations } \\
\hline \multicolumn{8}{|l|}{ Gibberellins } \\
\hline GA1 & $0.000 * * *$ & $0.000 * * *$ & $0.000 * * *$ & $0.003 * *$ & $0.000 * * *$ & $0.054 \bullet$ & 0.289 \\
\hline GA3 & $0.000 * * *$ & $0.002 * *$ & $0.000 * * *$ & $0.050 *$ & $0.000 * * *$ & 0.686 & 0.790 \\
\hline GA4 & $0.000 * * *$ & $0.027 *$ & $0.000 * * *$ & 0.118 & $0.000 * * *$ & 0.898 & 0.871 \\
\hline GA7 & $0.000 * * *$ & 0.746 & $0.000 * * *$ & 0.111 & $0.000 * * *$ & 0.193 & 0.134 \\
\hline \multicolumn{8}{|l|}{ Cytokinins } \\
\hline iPR & $0.000 * * *$ & $0.000 * * *$ & $0.000 * * *$ & $0.021 *$ & $0.000 * * *$ & $0.000 * * *$ & $0.000 * * *$ \\
\hline iP & $0.000 * * *$ & $0.000 * * *$ & $0.004 * *$ & $0.000 * * *$ & $0.003 * *$ & $0.000 * * *$ & $0.000 * * *$ \\
\hline tZR & 0.216 & $0.000 * * *$ & $0.000 * * *$ & $0.059 \bullet$ & $0.004 * *$ & $0.000 * * *$ & $0.001 * * *$ \\
\hline \multirow{2}{*}{\multicolumn{8}{|c|}{ Auxins }} \\
\hline & & & & & & & \\
\hline IAA & $0.000 * * *$ & 0.236 & $0.000 * * *$ & 0.187 & $0.000 * * *$ & 0.337 & 0.321 \\
\hline IBA & $0.000 * * *$ & $0.001 * * *$ & $0.000 * * *$ & $0.046 *$ & $0.000 * * *$ & 0.775 & 0.705 \\
\hline \multicolumn{8}{|l|}{ Abscisic acid } \\
\hline $\mathrm{ABA}$ & $0.000 * * *$ & 0.146 & $0.000 * * *$ & 0.289 & $0.000 * * *$ & 0.490 & 0.527 \\
\hline \multicolumn{8}{|c|}{ Defense signaling } \\
\hline SA & $0.000 * * *$ & $0.000 * * *$ & $0.073 \bullet$ & $0.020 *$ & 0.107 & 0.847 & 0.658 \\
\hline OPDA & $0.000 * * *$ & $0.004 * *$ & $0.000 * * *$ & 0.142 & $0.000 * * *$ & 0.221 & 0.152 \\
\hline JA & $0.012 *$ & $0.003 * *$ & $0.001 * * *$ & 0.541 & $0.000 * * *$ & 0.737 & 0.380 \\
\hline JA-Ile & $0.000 * * *$ & $0.022 *$ & $0.000 * * *$ & 0.141 & $0.000 * * *$ & 0.231 & 0.210 \\
\hline \multicolumn{2}{|l|}{ Phytohormone } & Susceptibility & \multicolumn{2}{|c|}{ Date } & eptibility $\times$ date & & \\
\hline \multicolumn{8}{|c|}{ Gall-induced phytohormone concentration changes } \\
\hline \multicolumn{8}{|c|}{ Gibberellins } \\
\hline GA1 & \multicolumn{2}{|r|}{$0.000 * * *$} & \multicolumn{2}{|c|}{$0.000 * * *$} & 0.131 & & \\
\hline GA3 & \multirow{2}{*}{\multicolumn{2}{|c|}{$0.002 * *$}} & \multicolumn{2}{|c|}{$0.000 * * *$} & 0.368 & & \\
\hline GA4 & $0.000 * * *$ & & \multicolumn{2}{|c|}{$0.000 * * *$} & 0.476 & & \\
\hline & & 0.147 & 0.00 & $0 * * *$ & $0.091 \bullet$ & & \\
\hline \multicolumn{8}{|l|}{ Cytokinins } \\
\hline \multicolumn{2}{|l|}{ iP } & $0.001 * * *$ & \multicolumn{2}{|c|}{$0.026 *$} & $0.004 * *$ & & \\
\hline iPR & & $0.081 \bullet$ & 0.00 & $0 * * *$ & $0.002 * *$ & & \\
\hline $\mathrm{tZ}$ & & $0.028 *$ & $0.00^{\top}$ & $7 * *$ & $0.003 * *$ & & \\
\hline tZR & & 0.347 & 0.02 & & $0.057 \bullet$ & & \\
\hline Auxins & & & & & & & \\
\hline IAA & & $0.070 \bullet$ & 0.00 & $0 * * *$ & 0.174 & & \\
\hline IBA & & $0.002 * *$ & 0.00 & $0 * * *$ & 0.289 & & \\
\hline Abscisic acid & & & & & & & \\
\hline $\mathrm{ABA}$ & & $0.012 *$ & 0.00 & $0 * * *$ & 0.319 & & \\
\hline Defense signal & & & & & & & \\
\hline SA & & $0.000 * * *$ & 0.00 & $0 * * *$ & $0.000 * * *$ & & \\
\hline OPDA & & $0.013 *$ & 0.00 & $0 * * *$ & 0.485 & & \\
\hline $\mathrm{JA}$ & & $0.002 * *$ & 0.00 & $1 * * *$ & 0.233 & & \\
\hline JA-Ile & & $0.005 * *$ & 0.00 & $0 * * *$ & $0.009 * *$ & & \\
\hline
\end{tabular}

a Statistical differences are indicated as follows: three asterisks (***) indicate $P \leq 0.001$, two $(* *) P \leq 0.01$, one $(*) P \leq 0.05$, and a black dot $\bullet P \leq 0.1$. iPR $=$ 6- $(\Delta 2$-isopentenyl $)$ adenine riboside; $\mathrm{P}=6$ - $(\Delta 2$-isopentenyl $)$ adenine; $\mathrm{tZR}$ trans-zeatin riboside; $\mathrm{tZ}=$ trans-zeatin; $\mathrm{IAA}=$ indole 3 -acetic acid; IBA $=$ indole3-butanoic acid; SA = salicylic acid; OPDA = 13-epi-12-oxo-phytodienoic acid; JA = jasmonic acid; JA-Ile = jasmonoyl-isoleucine. 


\section{A Gibberellins}
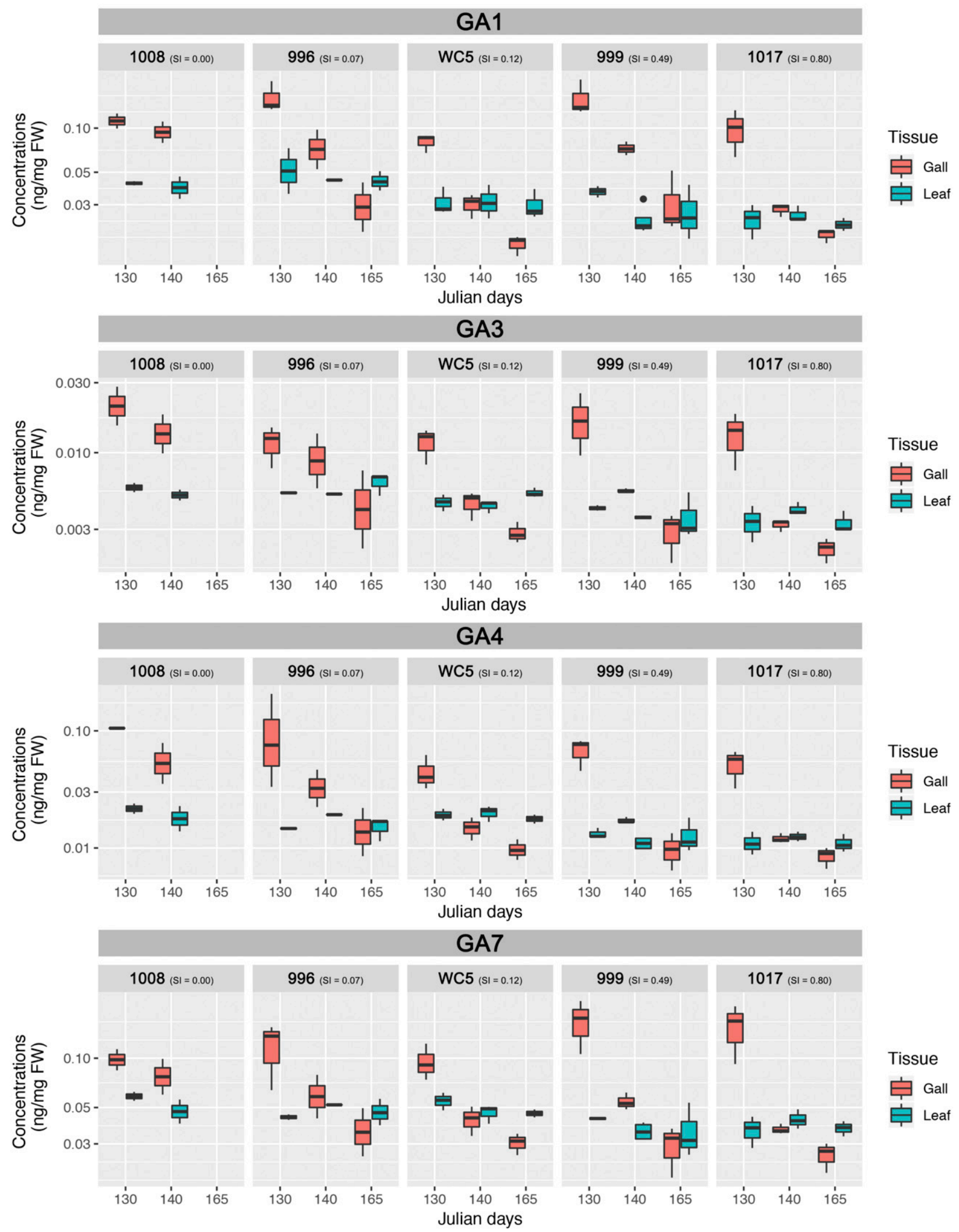

(Continued)

Fig. 2. Phytohormone levels in ungalled control leaves and galls for five individual tree genotypes. A, Gibberellins (GAs), B, cytokinins, C, auxins, D, abscisic acid, E, salicylic acid and jasmonic acid defense signaling. Data are presented in nanograms per milligram of fresh weight, and boxplots display the minimum, first quartile (Q1), median, third quartile (Q3), and maximum for each phytohormone, tissue, tree genotype, and collection date. Note that no gall was found on the most-resistant tree genotype 1008 on Julian day 165. 
Fig. 2. (Continued from previous page)

\section{B Cytokinins}
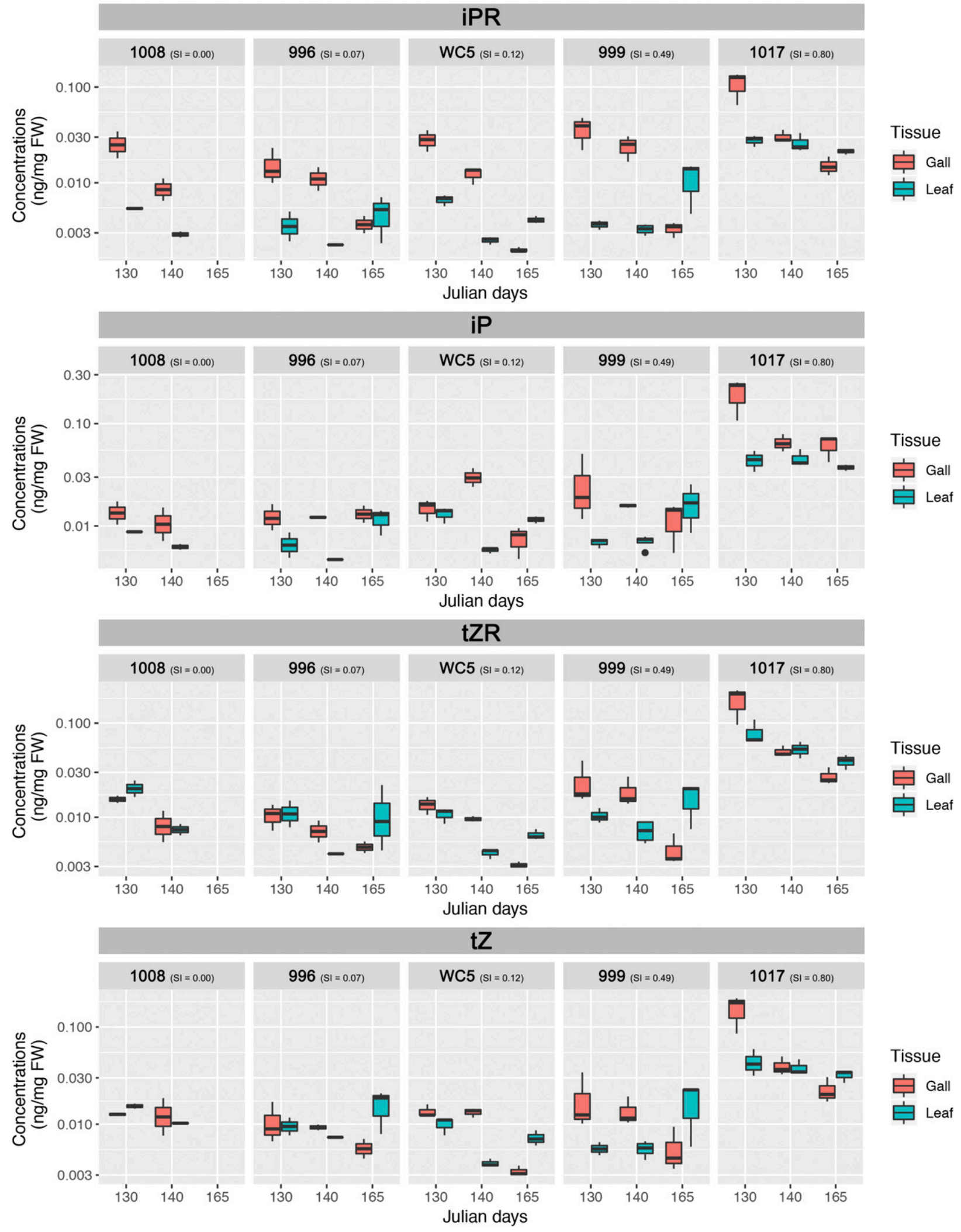

(Continued) 
significantly more concentrated in galls of the most-resistant tree genotype 1008 (GLM procedure, Tukey's HSD posthoc test, $P \leq 0.05)$ and on the first sampling date of all the genotypes (GLM procedure, Tukey's HSD posthoc test, $P \leq 0.05$ (Fig. 2C]).

Abscisic acid (ABA). The ABA concentration was significantly greater in leaves of the most-resistant tree genotype (1008) than in others (GLM procedure, Tukey's HSD posthoc test, $P \leq 0.05)$ and on the first sampling date (GLM procedure, Tukey's HSD posthoc test, $P \leq 0.05$ (Fig. 2D). Concentration of ABA was significantly greater in galls of the two most-resistant tree genotypes (1008 and 996) (GLM procedure, Tukey's HSD posthoc test, $P \leq 0.05)$ and on the first sampling date of all the genotypes (GLM procedure, Tukey's HSD posthoc test, $P \leq 0.05$ (Fig. 2D]).

Defense signaling. Concentrations in leaves of all the defense-related phytohormones (SA, 13-epi-12-oxo-phytodienoic acid [OPDA], jasmonic acid (JA), jasmonoyl-isoleucine [JA-Ile]) were significantly greater on the most-resistant tree genotype 1008 than in leaves of all the other genotypes (GLM procedure, Tukey's HSD posthoc test, $P \leq 0.05$ ). Concentrations of these four phytohormones did not change with sampling date (GLM procedure, $P=0.589$ for SA, 0.078 for OPDA, 0.764 for JA, and 0.604 for JA-Ile [Fig. 2E]). In galls, SA and OPDA exhibited significantly greater concentrations on the two

Fig. 2. (Continued from previous page)

\section{Auxins}

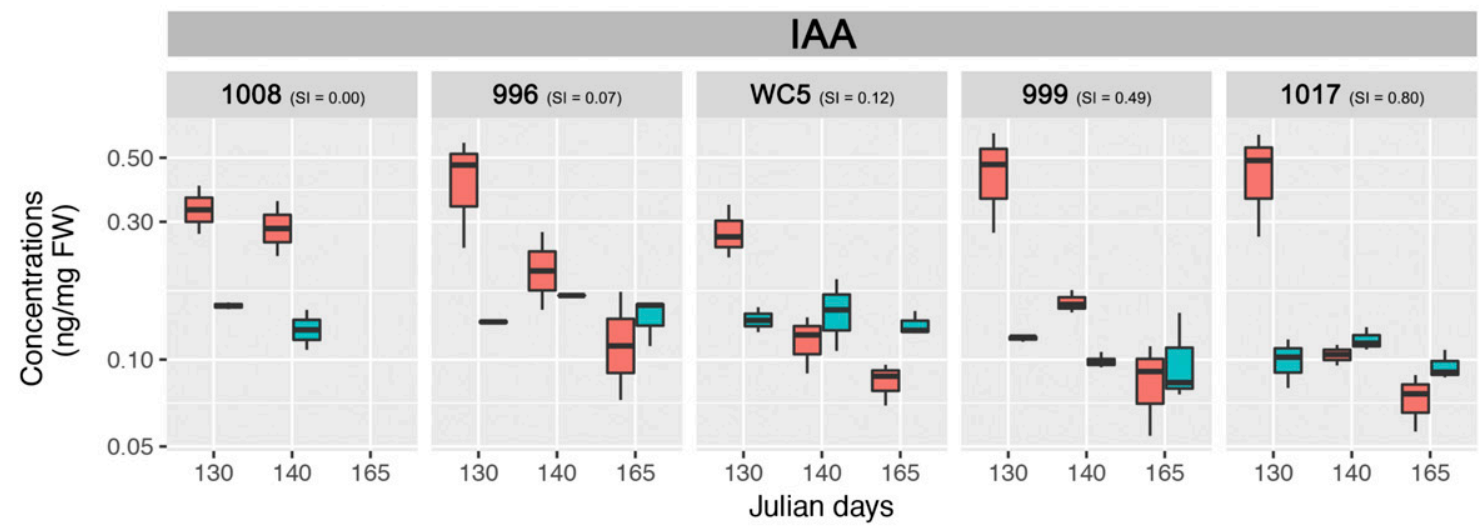

Tissue

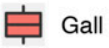

Leaf

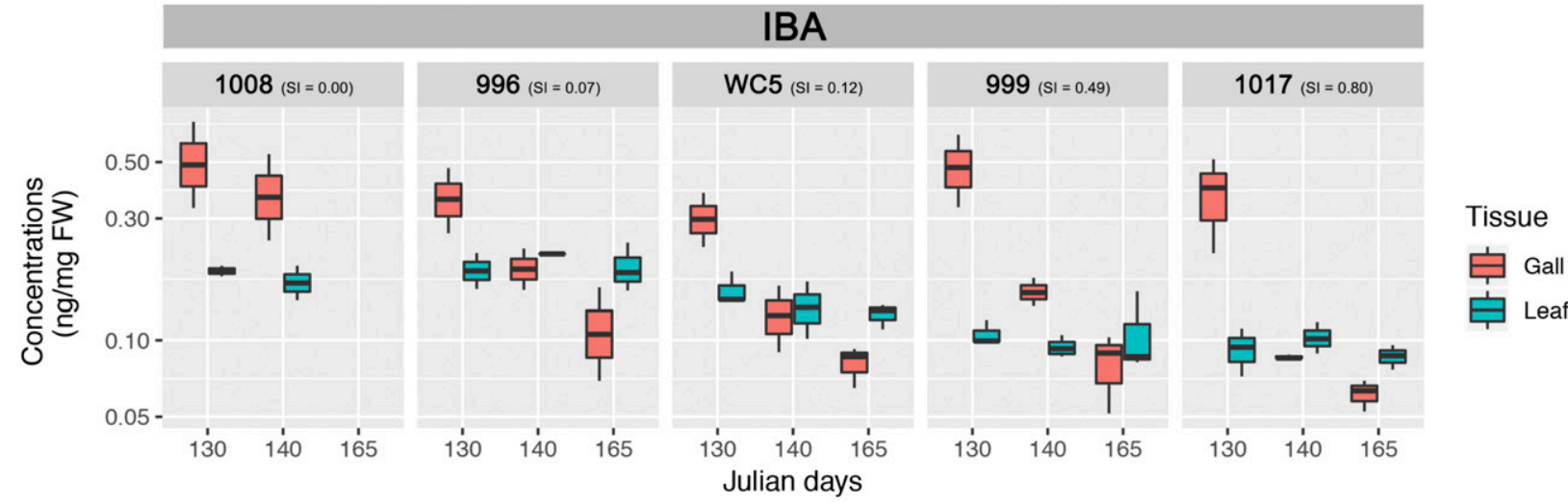

\section{Abscisic acid}

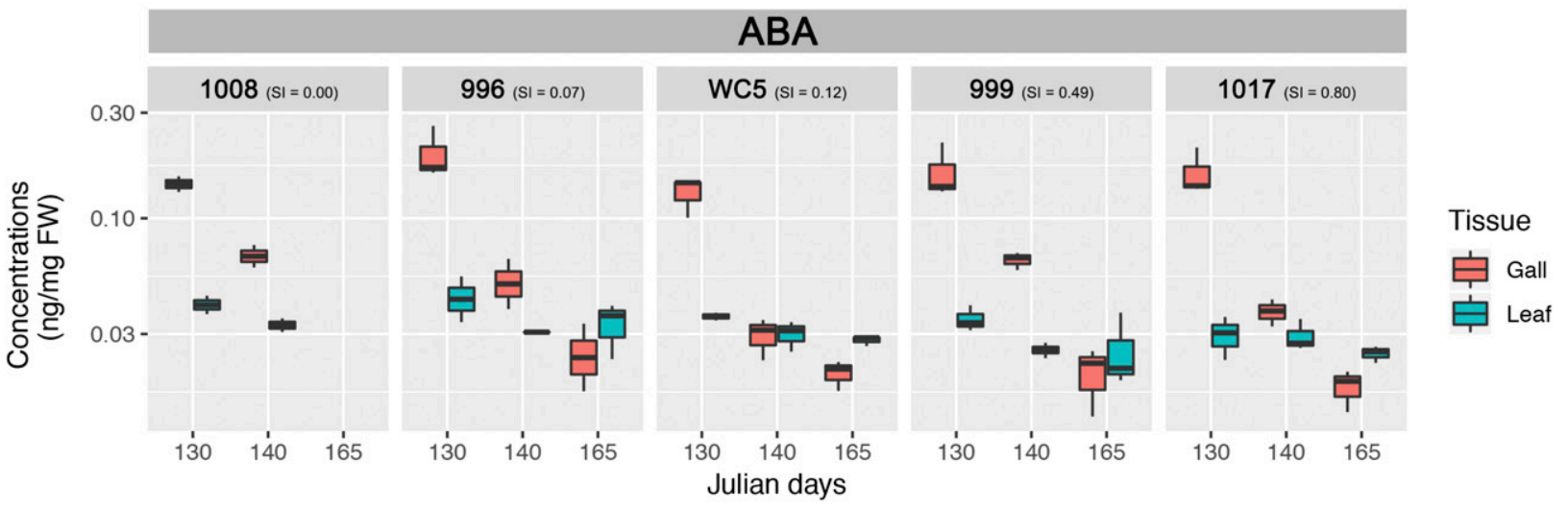


Fig. 2. (Continued from previous page)

\section{E Defenses}
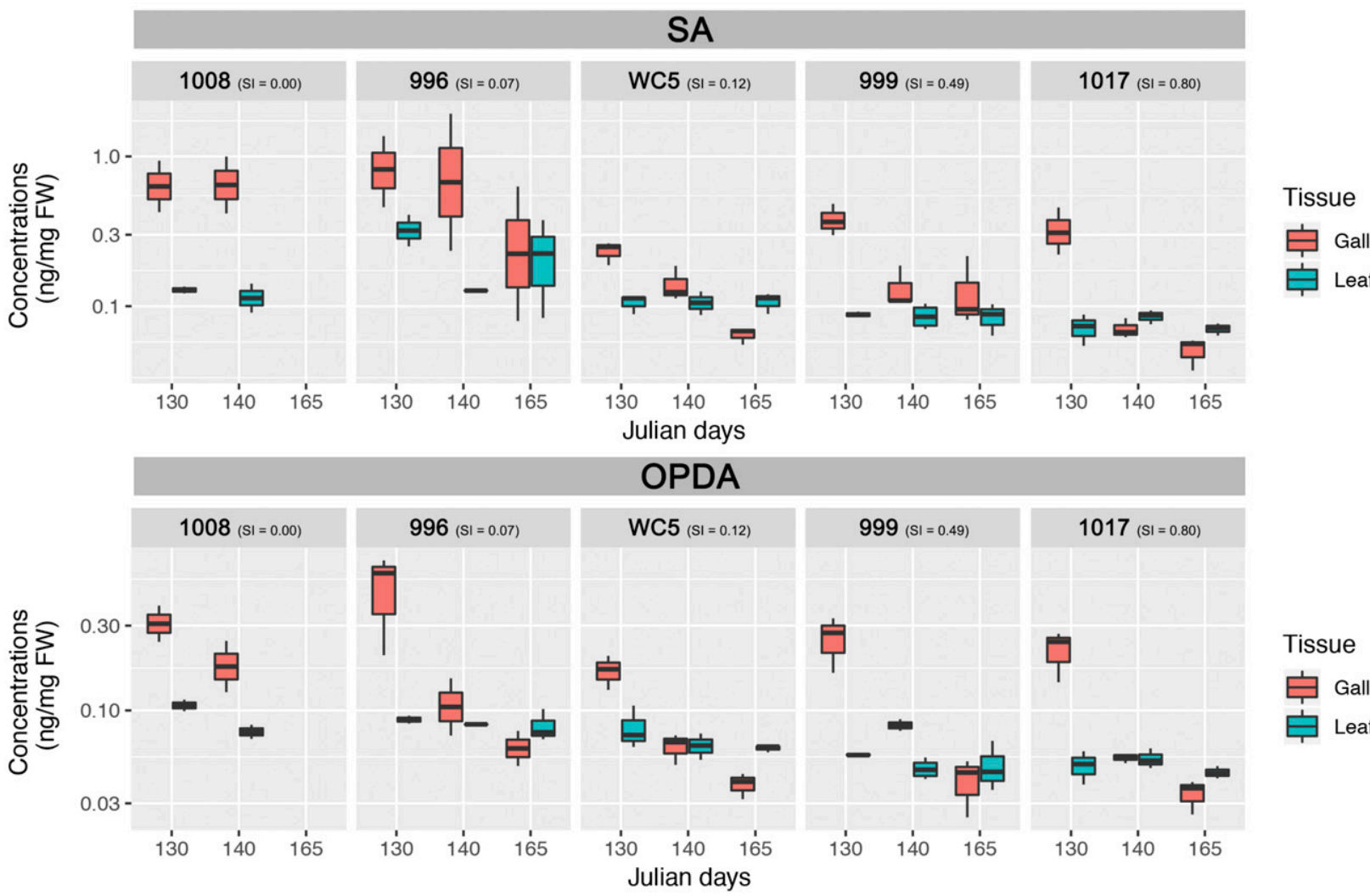

Tissue

官 Gall Leaf

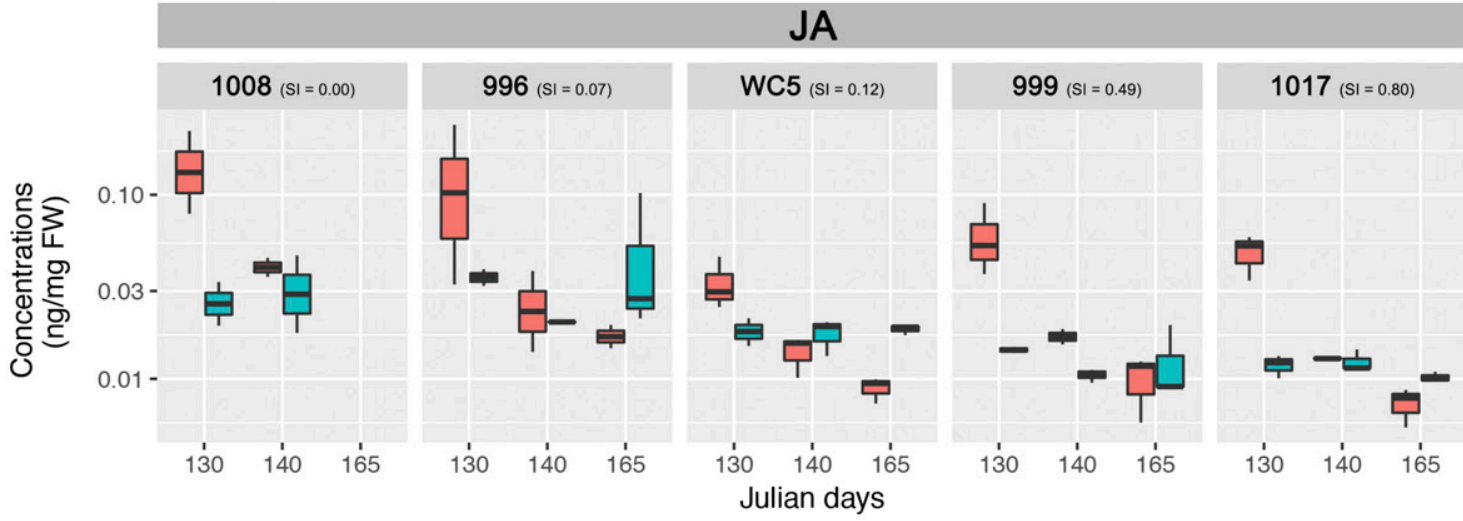

Tissue

宁 Gall 它 Leaf

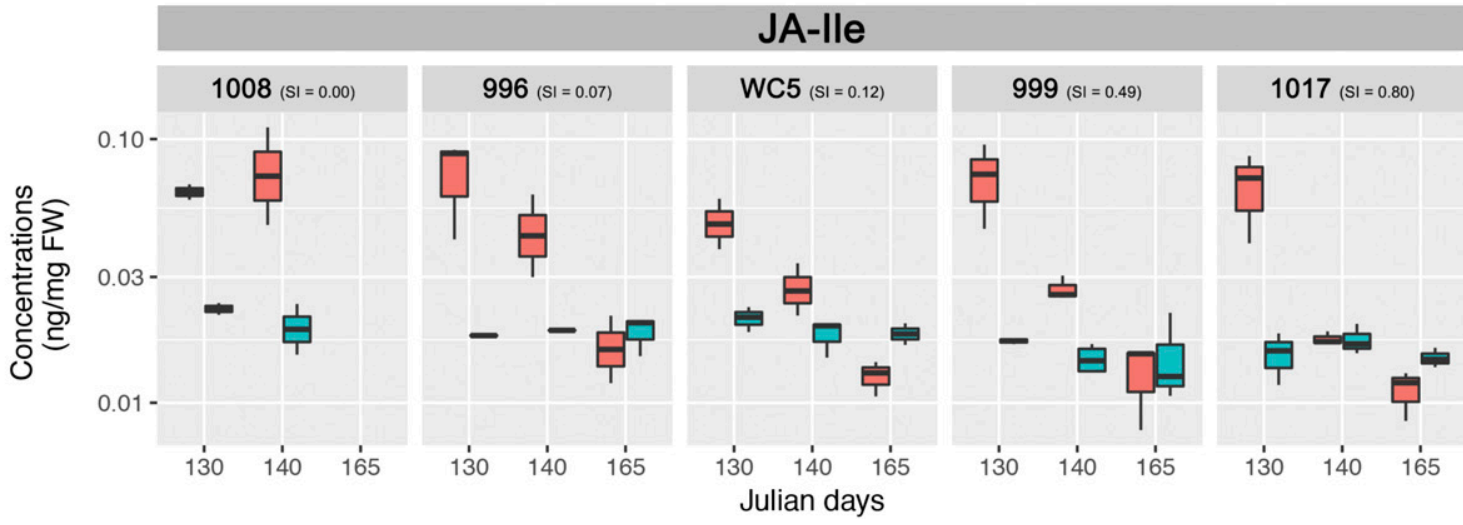

Tissue

Gall

它 Leaf 
most-resistant tree genotypes (1008 and 996) (GLM procedure, Tukey's HSD posthoc test, $P \leq 0.05$ ), while JA and JA-Ile were most concentrated on the most-resistant tree genotype (1008) only (GLM procedure, Tukey's HSD posthoc test, $P \leq 0.05$ ). Concentrations of all four phytohormones were greatest in galls on the first sampling date (GLM procedure, Tukey's HSD posthoc test, $P \leq 0.05$ ), followed by declines for all the tree genotypes (Fig. 2E).

\section{Phytohormonal responses to galling.}

To determine whether the greater concentrations of phytohormones in galls as compared with ungalled leaves represents changes induced by galling, we examined the differences between gall and ungalled control leaf values on 36 individual trees from our study population representing the same range of susceptibility genotypes. A GLM, two-way MANOVA indicated that phytohormone signature differences between gall and leaf values differed significantly among tree genotype susceptibility and sampling date (GLM, two-way MANOVA, $P \leq 0.001$ for each factor [Table 2]). An interaction between these two factors was also significant (GLM, two-way MANOVA, $P \leq 0.001$ for susceptibility $\times$ date [Table 2]). Tukey's HSD posthoc tests indicated that the increases of all 15 phytohormones differed among dates (GLM procedure, Tukey's HSD posthoc test, $P \leq 0.05)$. In each case, concentration differences on either the first or first and second dates were significantly greater than differences seen on subsequent dates (Fig. 3).

All individual phytohormone concentration differences (GLM procedure, Tukey's HSD posthoc test, $P \leq 0.05$ ) but two (GLM procedure, $P=0.147$ for GA7 and 0.347 for tZR [Table 3]) varied among tree genotypes as well. In a pattern similar to measures for galls and leaves alone, changes in concentrations of GAs, AUXs, ABA, and defense-related phytohormones were greatest in the most-resistant tree genotypes (GLM procedure, Tukey's HSD posthoc test, $P \leq 0.05$ ), while changes in CKs were greatest in the most-susceptible tree genotype 1017 (GLM procedure, Tukey's HSD posthoc test, $P \leq 0.05$ [Fig. 3]).

\section{Heritability of differential constitutive phytohormone concentrations and induced responses.}

We quantified genotype-related variation in phytohormone concentrations in galls and ungalled control leaves by estimating broad-sense heritabilities $\left(\mathrm{H}_{\mathrm{B}}^{2}\right)$. We found significant $(P \leq 0.05) \mathrm{H}_{\mathrm{B}}^{2}$ estimates for constitutive concentrations of all phytohormones except ABA and JA-Ile. Estimates ranged from 0.39 (GA7) to 0.93 (JA) (Table 4).

We estimated $\mathrm{H}_{\mathrm{B}}^{2}$ of concentration differences between galls and ungalled control leaves on the same trees (induced response) (Table 4). We found significant $(P \leq 0.05) \mathrm{H}_{\mathrm{B}}^{2}$ estimates of induced concentration differences ranging from 0.28 (GA1) to 0.66 (GA4) for all GAs but GA7, one AUX (IBA), and for SA among defense-related signals.

We also plotted reaction norms (RN) (Fig. 4) to visualize the relationships between phytohormone responses to galling and each tree genotype. The RN slopes for GA3, GA4, IBA, SA, JA, and JA-Ile on the resistant tree genotype 1008 (and 996 for SA) were significantly steeper than the slopes on the other genotypes (GLM procedure, Tukey's HSD posthoc test, $P \leq 0.05$ [Fig. 4]), indicating significant genotypic responses. Similarly, the RN slope for iP on susceptible tree genotype 1017 was steeper than slopes of all CK RNs on the other genotypes (GLM procedure, Tukey's HSD posthoc test, $P \leq 0.05$ [Fig. 4]). These responses also changed significantly with collection dates for iPR, iP, tZ, SA, and JA-Ile, and marginally for GA7 and tZR (Table 4) as leaves became less responsive.

\section{DISCUSSION}

Phytohormones have pivotal roles in initiating and regulating plant growth and development as well as in coordinating defense responses. The ultimate plant phenotype is shaped by the activities of multiple phytohormones and their interactions (Davies 2010; Pieterse et al. 2012). Insect gall growth and development should be no exception.

In this study, we surveyed phytohormone concentrations in ungalled leaves of five Populus angustifolia genotypes that differ in susceptibility (ranging from 0 to $80 \%$ ) to gall formation by the aphid Pemphigus betae (constitutive levels). We also assessed phytohormone concentrations in Pemphigus betae galls from these five tree genotypes and compared phytohormone concentrations in galls with those in matched leaves on the same individual trees, to assess the hormonal responsiveness of the trees to galling. The 15 phytohormones chosen for study are involved in either growth and development regulation or stress and defense responses. The genetic correlation between phytohormone profiles and tree resistance to galling was examined for both constitutive (leaf) and induced (difference between leaf and gall) levels.

\section{Growth regulators in resistant and susceptible poplar genotypes.}

GAs (GA1, GA3, GA4, and GA7) and AUXs (IAA and IBA) had greater constitutive concentrations (up to 2.3 times) in leaves of the three most-resistant tree genotypes (1008, 996, and WC5) than in the two least-resistant genotypes (999 and 1017). In contrast, CKs (iPR, iP, tZR, and tZ) had up to 7.8 times greater constitutive concentrations in leaves of the most-susceptible tree genotype, i.e., 1017.

GAs regulate growth and influence various developmental processes, including stem elongation, germination, dormancy, flowering, leaf and fruit senescence, and starch hydrolysis, among other things (Huot et al. 2014). Concentrations of all four GA forms known to be active tended to be or were significantly elevated in younger galls on all tree genotypes, at least for the first collection date (up to 5.1 times). Concentration differences among genotypes and between galls and leaves waned as leaves and galls aged.

There are relatively few studies of GAs in a resistance context (Li et al. 2017; Moosavi 2017; Tokuda et al. 2013). GAs stimulated plant innate defense responses and increased tomato resistance to the root galling nematode Meloidogyne javanica (Moosavi 2017). A study of Cicadulina bipunctata leafhoppers showed that GA1 and GA4 concentrations were both significantly decreased in insect galls on a susceptible variety of corn (Zea mays) (Tokuda et al. 2013). The opposite pattern was shown in galls induced by the gall wasp Leptocybe invasa on Eucalyptus sp., with more GAs in small and medium galls than in their respective controls on both susceptible and resistant varieties ( $\mathrm{Li}$ et al. 2017). The decline in GA accumulation in galls from the first through the last collection dates on all tree genotypes is consistent with the findings of $\mathrm{Li}$ et al. (2017). Interestingly, JA signaling has been shown to suppress GA synthesis (Heinrich et al. 2013; Vidhyasekaran 2015) and GA signaling is antagonistic to JA-mediated responses to herbivores and may promote resistance responses to microbes (Moosavi 2017; Vidhyasekaran 2015). Yet, both JA and GA concentrations were constitutively elevated in galls on resistant trees from the first collection date. On the other hand, GAs can also suppress CK synthesis (Greenboim-Wainberg et al. 2005) and CK levels were minimal in galls on resistant plants on Julian day 130.

As was true for GAs, higher AUX concentrations (up to two times) were characteristic of leaves and galls on the moreresistant tree genotypes 1008, 996, and WC5. IAA and IBA concentrations were generally greater in galls than leaves (up to 4.5 times); this difference was greatest and only significant on the 


\section{A Gibberellins}
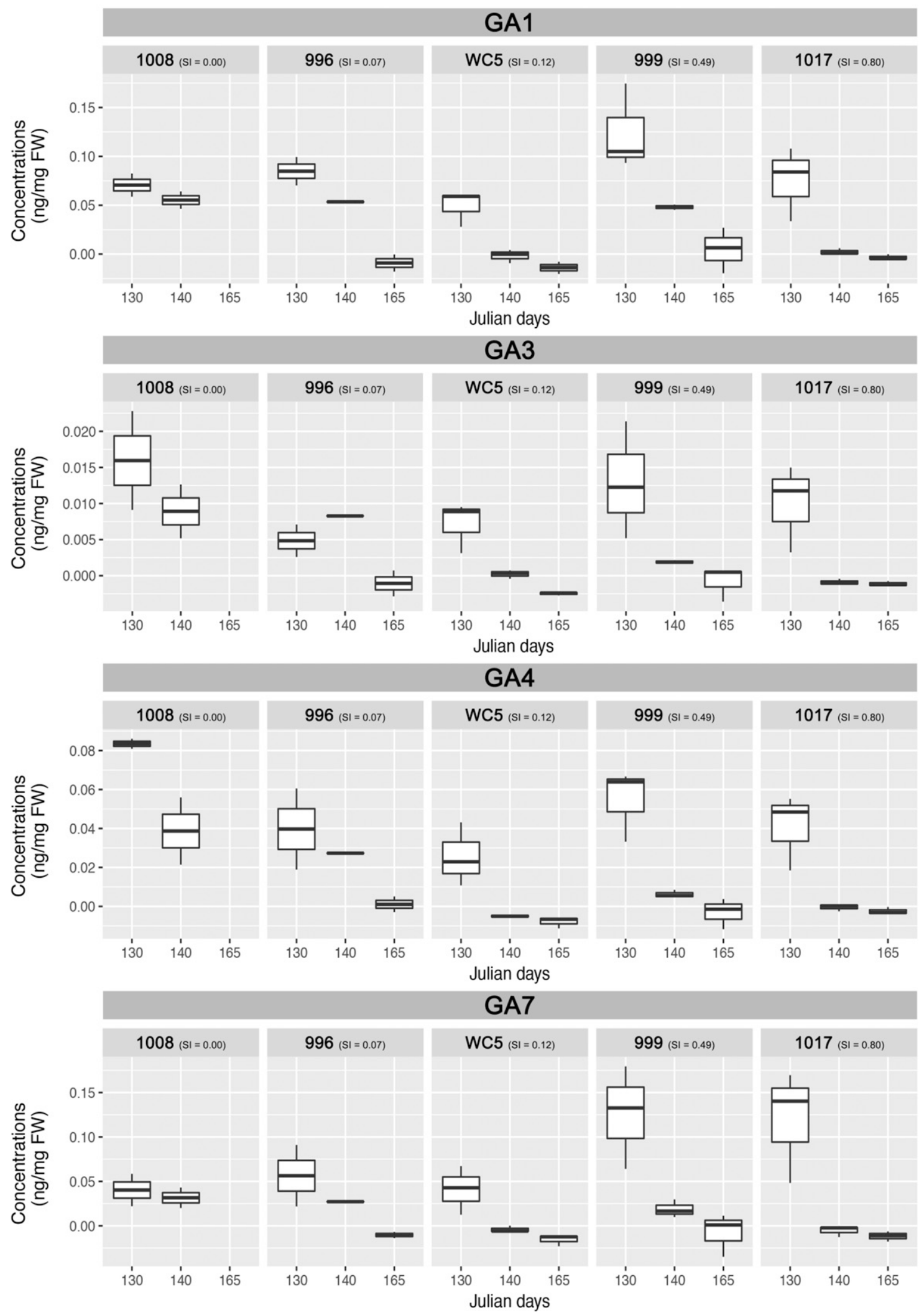

(Continued)

Fig. 3. Difference in phytohormone levels between galls and ungalled control for five individual tree genotypes. A, Gibberellins, B, cytokinins, C, auxins, D, abscisic acid, E, salicylic acid and jasmonic acid defense signaling. Data are presented in nanograms per milligram of fresh weight, and boxplots display the minimum, first quartile (Q1), median, third quartile (Q3), and maximum for each phytohormone, tree genotype, and collection date. Note that no gall was found on the most-resistant tree genotype 1008 on Julian day 165. 
Fig. 3. (Continued from previous page)

\section{B Cytokinins}
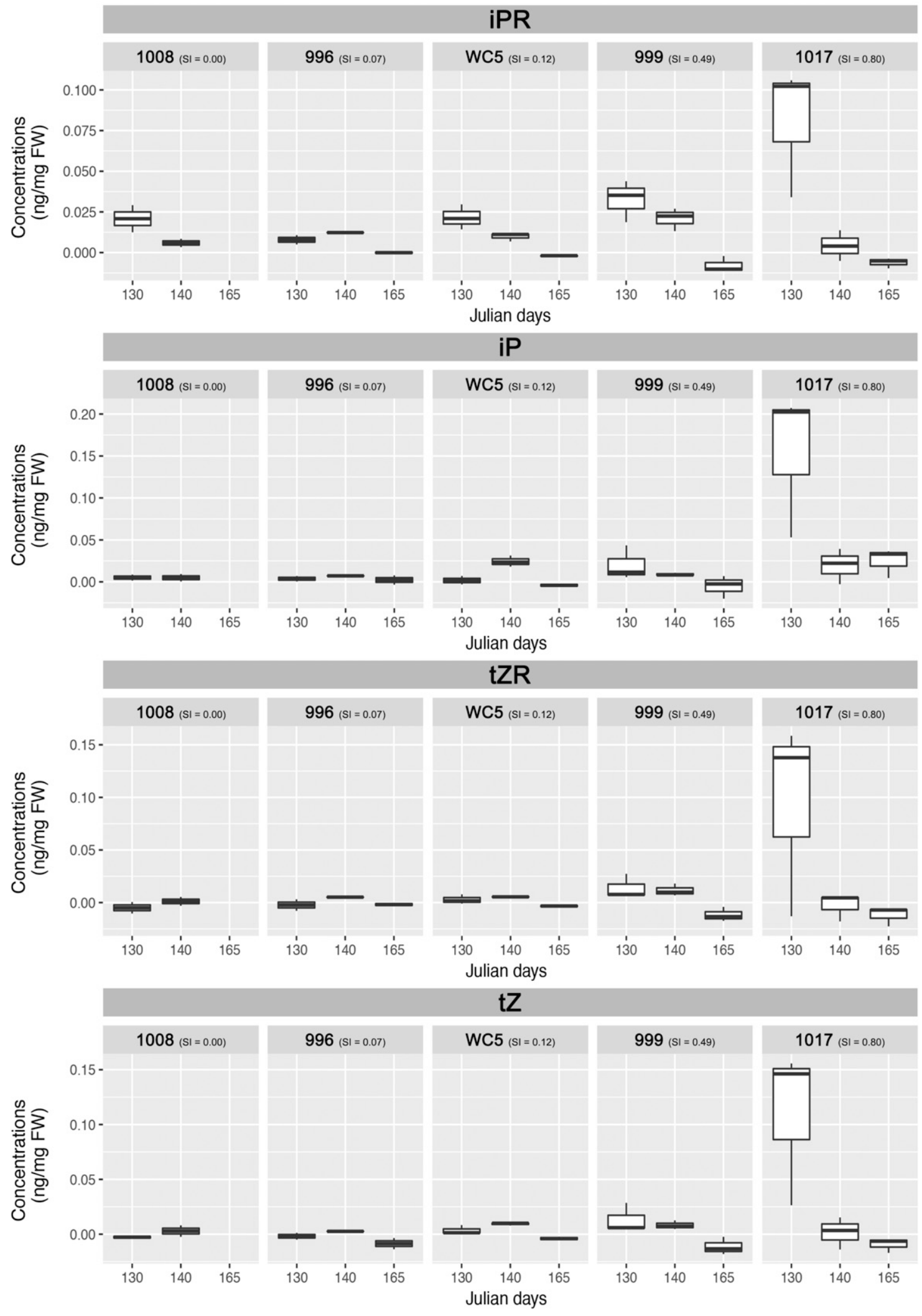
most-resistant tree genotype 1008. AUX maxima are generally required for organ location, growth and development, and for tissue bending (Benková et al. 2003; Liscum et al. 2014), which is evident in Pemphigus betae galls (Richardson et al. 2017). Gall formation involves cell hypertrophy and tissue hyperplasia (Richardson et al. 2017) (Fig. 5), which are regulated by IAA (Bandurski et al. 1995; Davies 2010; Raman et al. 2005). In addition, since plant innate immunity to pathogens is negatively influenced by auxin signaling (Naseem et al. 2015), high auxin concentrations could contribute to resistance against insects requiring microbes for host-plant manipulation (Zhang et al. 2017).
As was seen for all the phytohormones we measured, AUX concentrations in galls declined after our first sampling date. Our analysis was performed on full-sized galls, and the absence of increased AUX concentrations in galls for the late collection dates suggest that galls might not require high AUX concentrations beyond some maturation point. Byers et al. (1976) and Mapes and Davies (2001a) also reported that levels of AUX bioactivity declined with the developmental age of the galls they studied. Whole-gall sampling also may not reflect active concentrations if localization of AUXs is more important than total concentrations in the gall (Bedetti et al. 2014). Further investigations will be needed to clarify the role of AUX in this system.

Fig. 3. (Continued from previous page)

\section{Auxins}
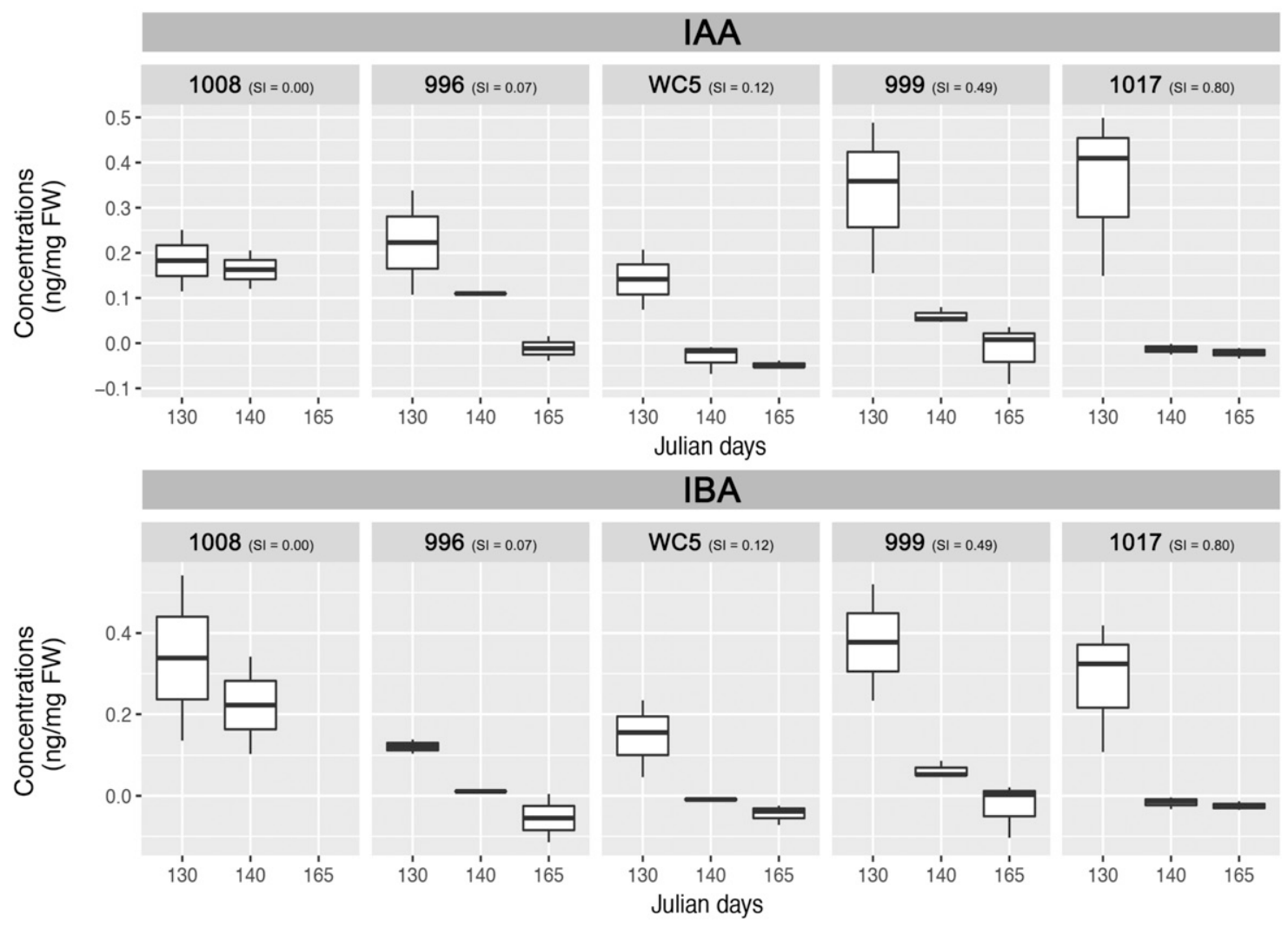

\section{Abscisic acid}

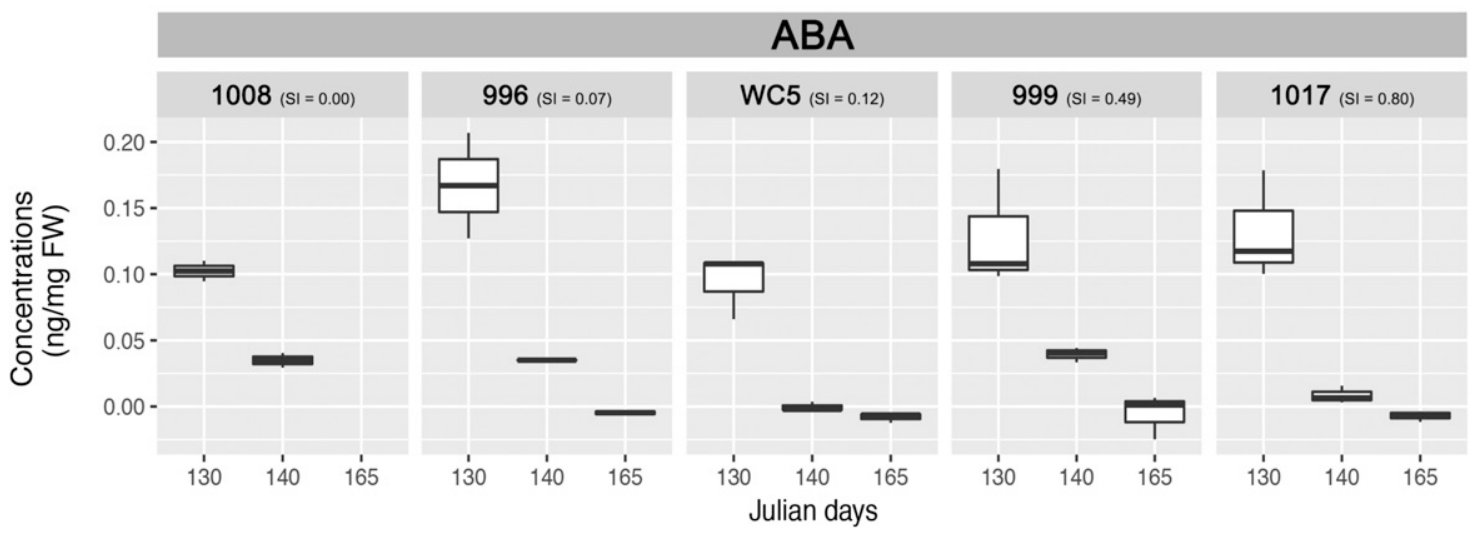


Fig. 3. (Continued from previous page)

\section{E Defenses}
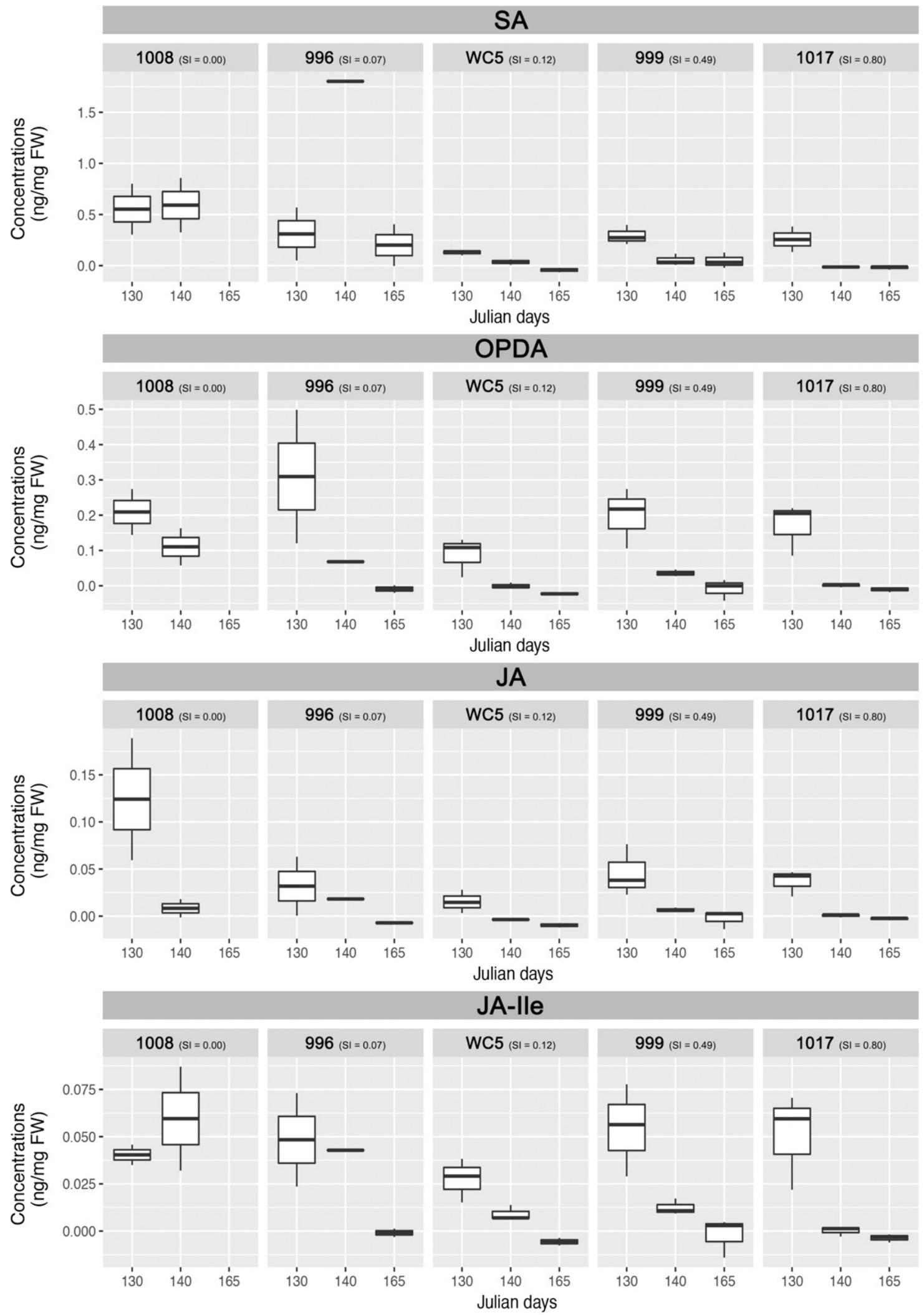

Vol. 32, No. 6, 2019 / 665 
The distribution of CK concentrations among tree genotypes was generally the opposite of that for all the other phytohormones we studied. All CK concentrations were significantly greater in leaves of susceptible genotype 1017 than in other trees on the first sampling date (up to 7.8 times), and concentrations in galls on 1017 were up to 16.5 times greater than in galls on more-resistant trees. CK concentrations in galls declined with time to levels at or near those in leaves, although those older leaf and gall levels were still significantly greater in 1017 than in other trees.

$\mathrm{CK}$ elevation in various galls has been reported many times $(\mathrm{Li}$ et al. 2017; Mapes and Davies 2001b; Tanaka et al. 2013; Tooker and Helms 2014; Yamaguchi et al. 2012), which is consistent with the role of CKs in regulating cell division, proliferation (Davies 2010), and sink strength (Roitsch and Ehneß 2000), key processes in gall growth (Carneiro et al. 2014; Giron et al. 2013, 2016; Gohlke and Deeken 2014; Richardson et al. 2017; Rohfritsch 1992; Stes et al. 2011; Tooker and Helms 2014). While iP and $\mathrm{tZ}$ are active $\mathrm{CK}$ forms, the ribosides may represent deactivated forms acting either as sinks or sources for CKs (Zürcher and Müller 2016), although the ribosides are active signals in some plant species (Holub et al. 1998).

CKs may play an important role in Populus angustifolia resistance to Pemphigus betae. Our results support previous data concluding that tree resistance is related to the inability of aphids to develop and maintain the strong sinks necessary for gall growth and development (Compson et al. 2011; Larson and Whitham 1991, 1997; Zinkgraf et al. 2016). Zinkgraf et al. (2016) showed that variation in two Populus angustifolia genes putatively involved in regulating sink-source relationships - a plant neutral invertase (NIN1) and an inhibitor of invertase (C/VIF1) - is associated with tree resistance to galling by Pemphigus betae. CKs are important regulators of invertases and sink strength (Roitsch and Ehneß 2000). Success of gall-forming bacteria Agrobacterium tumefaciens and Plasmodiophora brassicae depends on using exogenous CKs and increasing endogenous CK production to increase local sink strength (Boivin et al. 2016; Deeken et al. 2006; Gohlke and Deeken 2014), as is true for many non-galling plant pathogens and symbionts (Choi et al. 2011). Li et al. (2017) also reported that susceptible Eucalyptus varieties had higher levels of CKs ( $\mathrm{ZR}$ and $\mathrm{Z}$ ) than the resistant variety. The patterns we observed are consistent with the hypothesis that low constitutive and gall CKs may be a mechanistic basis of gall failure and tree resistance (Fig. 5).

\section{Stress response and defense signaling.}

ABA concentrations were elevated in galls on all tree genotypes for at least the first (up to 5.4 times) and often the second collection dates. Like elevated GAs, elevated ABA concentrations in galls may be characteristic of responses to aphid feeding. Increases of ABA transcripts or concentrations, or both, are involved in plant defense against aphids (Morkunas and Gabryś 2011) as well as caterpillars (Appel et al. 2014), and aphid feeding likely elicits a stress response (Tokuda et al. 2013). Straka et al. (2010) and Tooker and De Moraes (2011) found greatly elevated levels of ABA in galling psyllids and caterpillars but not in their galls, while Li et al. (2017) found no difference in ABA levels in susceptible and resistant control tissues but an increase in galled tissues in response to a wasp that was greater on the resistant Eucalyptus exserta variety. The role of ABA in galling remains obscure.

Defense signals (SA, JA precursor OPDA, JA, and JA-Ile) were up to 4.6 times more concentrated in leaves of moreresistant tree genotypes than on susceptible trees. Both JA and SA also were more concentrated in galls on the more-resistant tree genotypes than in susceptible ones for one or both of the first (up to 4.5 times) and, sometimes, second collection dates as well. The elevation of OPDA, JA, and JA-Ile concentrations in galls suggests that this biosynthetic pathway was activated there, although OPDA has independent signaling activity in some plant species (Stintzi et al. 2001). JA signaling is generally induced by necrotrophic pathogens and chewing herbivores (Erb et al. 2012; Pieterse et al. 2012; Thaler et al. 2012), while SA signaling is involved in resistance against biotrophic pathogens and fluid-feeding herbivores (Erb et al. 2012; Pieterse et al. 2012; Thaler et al. 2012). The leaves and galls we sampled were not sterile, so it is possible that ungalled leaves or galled tissues might have been responding to bacteria or fungi already present or introduced by the aphids in the galls. Since SA- and JA-signal concentrations varied together among tree genotypes, our results did not provide evidence of the well-established antagonism between SA and JA pathways, at least at the level of signal concentrations (Thaler et al. 2012).

Table 4. Heritability ${ }^{\mathrm{a}}$

\begin{tabular}{|c|c|c|c|c|c|c|}
\hline \multirow[b]{2}{*}{ Phytohormone/trait } & \multicolumn{3}{|c|}{ Constitutive } & \multicolumn{3}{|c|}{ Induced } \\
\hline & $\mathbf{H}_{\mathrm{B}}^{2}$ & CI.lower & CI.upper & $\mathbf{H}_{\mathrm{B}}^{2}$ & CI.lower & CI.upper \\
\hline \multicolumn{7}{|l|}{ Gibberellins } \\
\hline GA1 & $0.486 *$ & 0.212 & 0.883 & $0.280 *$ & -0.083 & 0.559 \\
\hline GA3 & $0.612 *$ & 0.389 & 1.008 & $0.393 *$ & 0.064 & 0.786 \\
\hline GA4 & $0.615 *$ & 0.389 & 0.988 & $0.660 *$ & 0.458 & 1.013 \\
\hline GA7 & $0.387 *$ & 0.062 & 0.774 & 0.000 & -0.411 & 0.000 \\
\hline \multicolumn{7}{|l|}{ Cytokinins } \\
\hline iPR & $0.852 *$ & 0.760 & 1.053 & 0.000 & -0.223 & 0.000 \\
\hline iP & $0.867 *$ & 0.785 & 1.054 & 0.178 & -0.210 & 0.356 \\
\hline tZR & $0.773 *$ & 0.632 & 1.036 & 0.000 & 0.000 & 0.000 \\
\hline $\mathrm{tZ}$ & $0.786 *$ & 0.651 & 1.051 & 0.000 & 0.000 & 0.000 \\
\hline \multicolumn{7}{|l|}{ Auxins } \\
\hline IAA & $0.453 *$ & 0.157 & 0.845 & 0.045 & -0.361 & 0.090 \\
\hline IBA & $0.781 *$ & 0.645 & 1.026 & $0.446 *$ & 0.141 & 0.847 \\
\hline \multicolumn{7}{|l|}{ Abscisic acid } \\
\hline ABA & 0.175 & -0.204 & 0.350 & 0.072 & -0.330 & 0.144 \\
\hline \multicolumn{7}{|l|}{ Defense signaling } \\
\hline Salicylic acid & $0.580 *$ & 0.339 & 0.949 & $0.385 *$ & 0.054 & 0.771 \\
\hline OPDA & $0.711 *$ & 0.535 & 1.040 & 0.216 & -0.170 & 0.432 \\
\hline Jasmonic acid & $0.928 *$ & 0.882 & 1.043 & 0.289 & -0.076 & 0.578 \\
\hline JA-Ile & 0.321 & -0.027 & 0.642 & 0.091 & -0.317 & 0.182 \\
\hline
\end{tabular}

${ }^{\mathrm{a}} \mathrm{H}_{\mathrm{B}}^{2}=$ broad-sense heritabilities; $\mathrm{CI}=$ confidence interval; an asterisk indicates statistical difference at $P \leq 0.05$; iPR $=6$ - $(\Delta 2$-isopentenyl) adenine riboside; $\mathrm{iP}=6$ - $(\Delta 2$-isopentenyl $)$ adenine; $\mathrm{tZR}$ trans-zeatin riboside; $\mathrm{tZ}=$ trans-zeatin; IAA = indole 3-acetic acid; IBA = indole-3-butanoic acid; OPDA = 13-epi12-oxo-phytodienoic acid; JA-Ile = jasmonoyl-isoleucine. 
The trees used in this study were clones planted in a common garden. This allowed us to identify significant heritability of between-genotype variation in phytohormone concentrations in leaves and galls. These traits may thus be subject to selection and play a role in the evolution of tree resistance to Pemphigus betae.

Elevated concentrations of defensive signals and growth phytohormones in more-resistant trees are not consistent with what is known about the complex regulation and interactions of these phytohormones. Several can suppress synthesis of others (e.g., ABA impact on GAs and SA synthesis, JA impact on SA and GA synthesis and vice versa, AUX impact on ABA synthesis [Adie et al. 2007; Noriega and Pérez 2017; Seo et al. 2006; Vidhyasekaran 2015; Zhang et al. 2009]); yet, all were elevated together in galls or leaves on resistant trees.

\section{Induced phytohormone changes.}

Galling increased concentrations of GA3, GA4, IBA, SA, JA, and JA-Ile on resistant tree genotypes 1008 (and 996 for SA) more than on susceptible genotypes, as seen in MANOVA results and an analysis of reaction norms comparing leaves and galls on the same individual trees. Resistance to Pemphigus betae galling in our study tree population was associated not only with constitutive concentrations of these phytohormones but, in many cases, with the degree to which their concentrations increased in galls as well. On the other hand, galling induced significantly greater concentrations of iP and $\mathrm{tZ}$ on

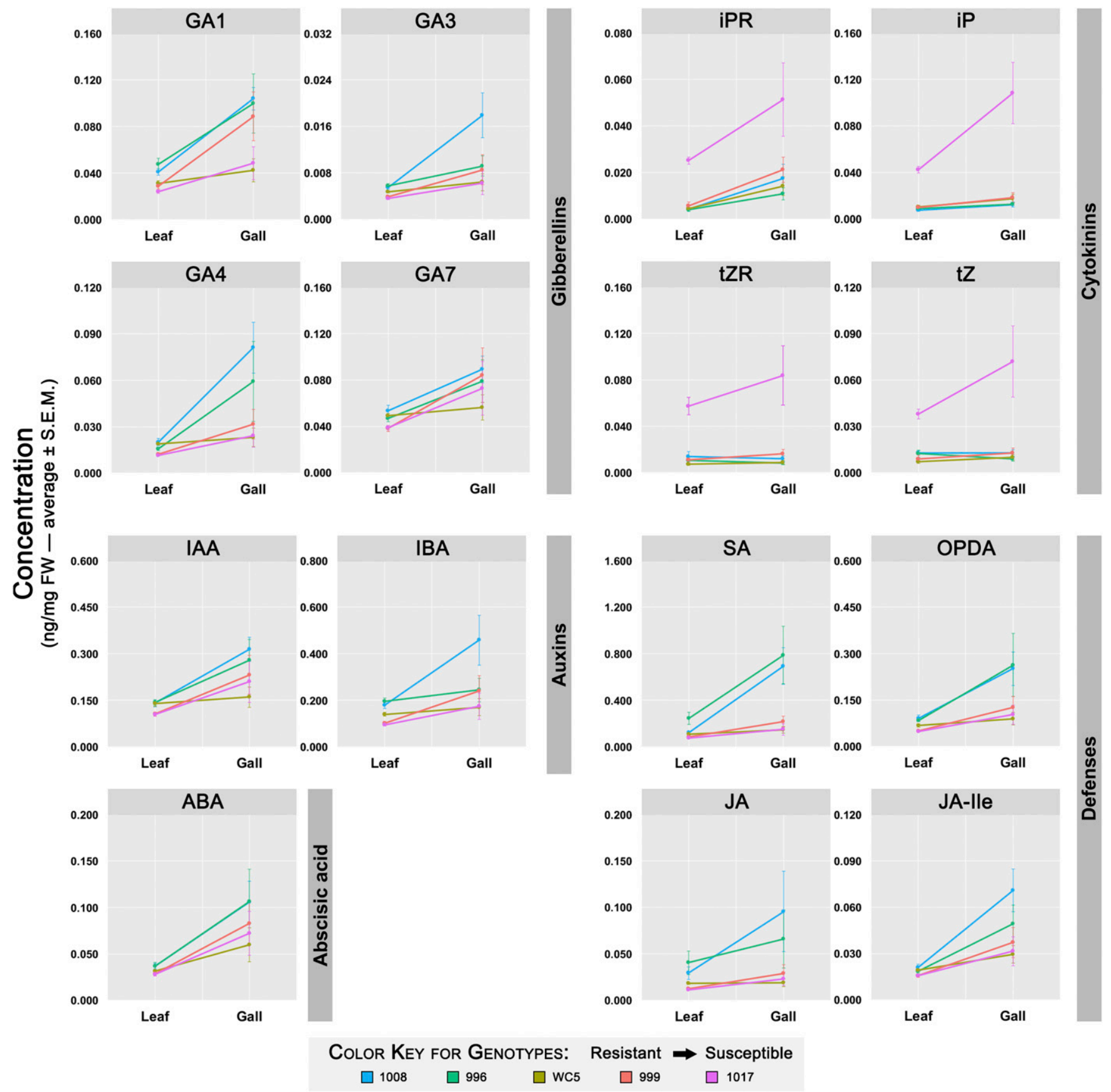

Fig. 4. Reaction norms showing gibberellin, cytokinin, auxin, abscisic acid, and defense signaling levels in ungalled control leaves and galls for five individual tree genotypes. Data are presented in nanograms per milligram of fresh weight, as average \pm standard error of the mean. 
susceptible genotype 1017 than on the other tree genotypes. Susceptibility was thus associated with higher constitutive CK concentrations and the degree to which iP increased in galls. These differences among tree genotypes suggest that phytohormone concentrations and induction have a heritable basis. Indeed, we found moderate to large estimates of $\mathrm{H}_{\mathrm{B}}^{2}$ for galling-induced changes in GA1, GA3, GA4, IBA, and SA. The contribution of the changes in susceptible tree genotype 1017 could not be discerned in an analysis across all five genotypes, but both concentrations and increases in concentrations of iP and $\mathrm{tZ}$ were significantly greater on that genotype than on the others.

While the role of variation in growth phytohormones in tree resistance to Pemphigus betae has not yet been experimentally tested, it is clear that the most-resistant tree genotype differed from the most-susceptible genotype by having enhanced constitutive or induced concentrations, or both, of some of the phytohormones known to be involved in growth as well as defense against pathogens and herbivores and by strikingly low concentrations of constitutive and induced CKs. This pattern is consistent with the view that galling success (initiation and maintenance) and tree susceptibility may depend on CK concentrations to elicit sink strength and suppress constitutive and induced concentrations of defense signals (Fig. 5).

The trees used in this study were classified as resistant to aphids on the basis of the number of galls found on a particular date. Since we studied relatively mature galls, we cannot associate phytohormone profiles with colonization or gall initiation. Many traits other than phytohormones that could influence early events differ between the two extreme genotypes (1008 and 1017), such as architecture, leaf nitrogen, condensed tannins, and salicortin (Bailey et al. 2006; Donaldson et al. 2006; Hwang and Lindroth 1997). Of course, many of these traits are influenced or regulated by phytohormones. Nonetheless, our results indicate that large differences in phytohormone profiles and the degree to which Pemphigus betae influences these distinguish resistant from susceptible tree genotypes, that these traits are heritable, and that they likely factor into the evolution of tree resistance to Pemphigus betae. This phytohormone variation may be partly responsible for the
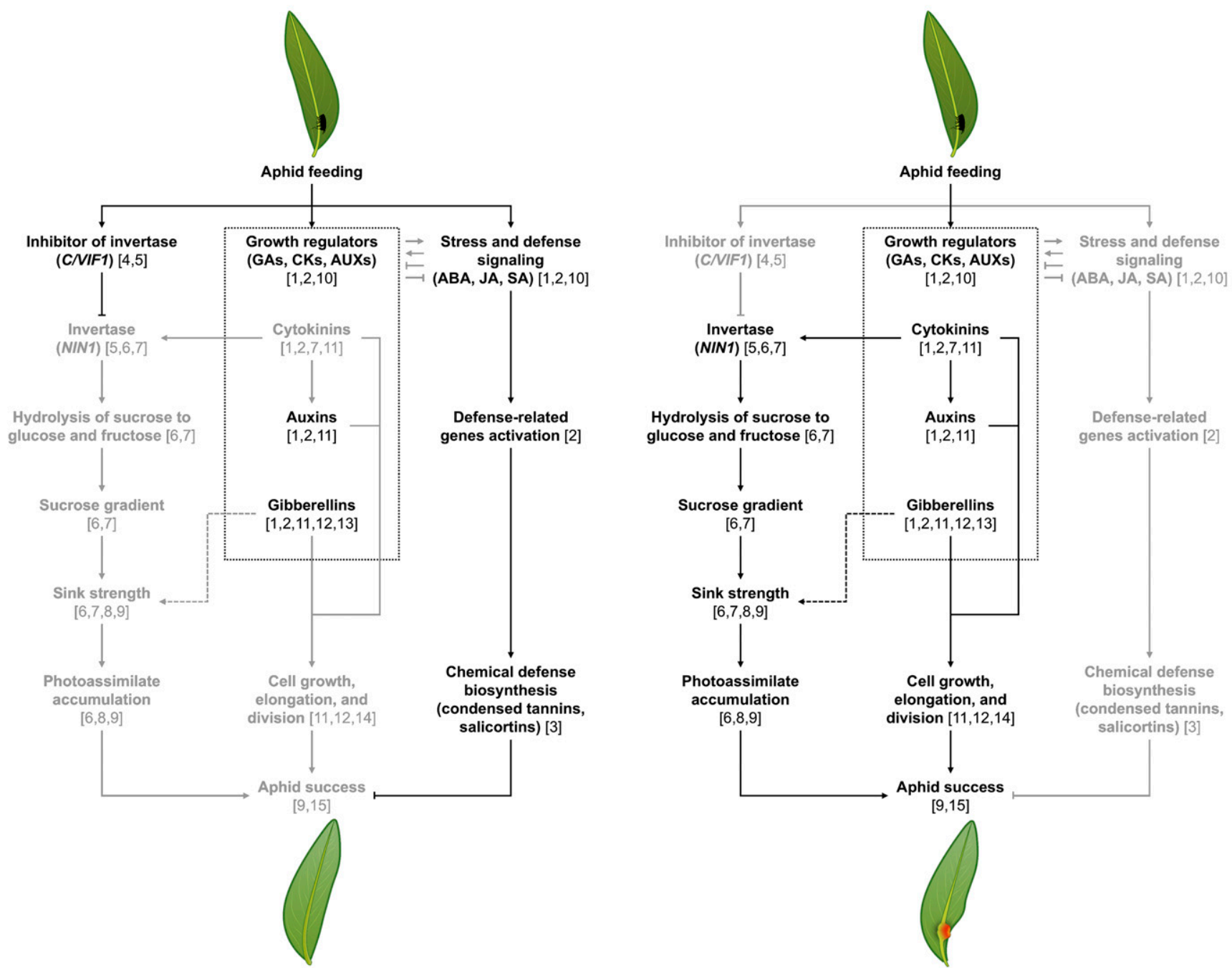

Fig. 5. Hypothetical mechanisms involved in poplar resistance to the gall-inducing aphid. This diagram is based on this work and previously published studies showing how the interaction between the galling aphid and its host plant could differ between the resistant and susceptible poplar genotypes. Steps in gray are likely to be constitutively or aphid-induced down-regulated, or both. Gibberellins can only increase the strength of an existing sink, hence the dashed lines. Sources: 1, this study; 2, Erb et al. 2012; 3, Bailey et al. 2006; 4, Bonfig et al. 2010; 5, Zinkgraf et al. 2016; 6, Roitsch and González 2004; 7, Roitsch and Ehneß 2000; 8, Larson and Whitham 1991; 9, Compson et al. 2011; 10, Robert-Seilaniantz et al. 2011; 11, Davies 2010; 12, Jones and Kaufman 1983; 13, Iqbal et al. 2011; 14, Richardson et al. 2017; and 15, Whitham 1989. 
demonstrated cascading impacts of tree genotype on community structure (arthropods, fungi, and birds), community stability, interaction networks, sink-source relationships, litter decomposition, and nutrient cycling (Bailey et al. 2006; Dickson and Whitham 1996; Keith et al. 2017; Schweitzer et al. 2005; Smith et al. 2011; Whitham et al. 2006, 2008) in the cottonwood-Pemphigus system. Detailed studies of phytohormonal features and functions during gall initiation and development in more tree genotypes could provide a better understanding of how Pemphigus betae has such far-ranging ecological impacts.

\section{MATERIALS AND METHODS}

\section{Biological system.}

The sugarbeet root aphid Pemphigus betae (Hemiptera: Aphididae) induces galls on leaves of the narrowleaf cottonwood Populus angustifolia (Salicaceae) (Fig. 1) (Harper 1959); Richardson et al. (2017) provides a more detailed view on Pemphigus betae gall development. Each gall (size of fully developed galls is about $25 \mathrm{~mm}$ long, about $6 \mathrm{~mm}$ deep [Harper 1959]) is induced by a single aphid (a fundatrix or stem mother) in the spring on poplar leaves (preferentially at their base) that are only a tenth to a quarter of their fully expended size (size of fully expanded leaf is 50 to $90 \mathrm{~mm}$ long, 10 to $25 \mathrm{~mm}$ wide [USDA-NRCS 2008]). Success in eliciting galls is influenced significantly by tree genotype (Compson et al. 2011; Whitham 1989; Zinkgraf et al. 2016), and Populus angustifolia genotypes differing significantly in resistance to Pemphigus betae galling have been identified and propagated in a common garden (Keith et al. 2010).

\section{Sample collection.}

Ungalled (control) and galled narrowleaf cottonwood leaves were collected (Ogden Nature Center, Ogden, UT, U.S.A.) on May 11, May 20, and June 14, 2009 (Julian days 130, 140, and 165 , respectively) on 18-year-old poplar trees from the common garden established in 1991 at the Ogden Nature Center. Leaves were immediately frozen in liquid nitrogen and were stored at $-80^{\circ} \mathrm{C}$ until analysis. By using trees from a common garden in which individual genotypes were planted at random, we standardized the growing conditions so that observed differences among genotypes were primarily due to innate genetic differences rather than environmental effects.

Leaves were harvested on five different poplar genotypes displaying a wide range of susceptibility to the gall-inducing aphid Pemphigus betae $(1017>999>$ WC5 > $996>1008)$ (Table 1) on all three of the collection dates mentioned above, except for the most-resistant tree genotype, 1008, for which no gall was found on Julian day 165. Susceptibility values of specific genotypes in the wild (determined by the number of successful galls per total number of attempts on naturally occurring trees) were highly correlated with susceptibility values on clones of the same genotypes grown in a common garden (determined by the survival of experimentally transferred stem mothers; $r=0.90, P<0.001$ [Whitham 1989]). Subsequent studies showed that these survival values, ranging from 0 to $75 \%$, remained stable for at least 20 years for individual tree genotypes (Zinkgraf et al. 2016). The galls were collected from the upper two thirds of the trees, because galls are generally concentrated on sexually mature branches (Kearsley and Whitham 1989), in which sink strength is greatest and leaves are larger, resulting in high survival and reproduction (Larson and Whitham 1997; Whitham 1983). To reduce the influence of gall sinks on nearby leaves, galled and ungalled leaves were collected from separate shoots, where a shoot was a group of leaves that originated from the same bud.
The colonizing stem mothers must form their galls during a very short window of about 3 days when the leaves have just emerged from the bud (bud flush is generally in late March to early April) (Kearsley and Whitham 1989; Keith et al. 2017); therefore, both control and galled leaves were about 8 weeks old when collected in late May and early June, and we can confidently say the galls were harvested at a very similar age. Both control and galled leaves were collected at the same time to make sure physiological differences observed are due to tree genotypes or presence of the galls and not due to phenological changes in the trees. Leaves were about $35 \mathrm{~mm}$ long and $18 \mathrm{~mm}$ wide, with fully developed galls that were about $10 \mathrm{~mm}$ long, $5 \mathrm{~mm}$ wide, and $2.5 \mathrm{~mm}$ deep. Galled leaves were dissected to remove leaf tissue surrounding the galls and the aphids inside the galls. The pooling scheme and sample sizes are provided in Table 1.

\section{Phytohormone quantification.}

Phytohormones. We chose to study phytohormones involved in growth and development (GAs, CKs, AUXs), source-sink relationships (CKs), response to stress (ABA), and defense signaling (SA, JA). To increase our ability to interpret results, we included several alternative forms of GAs, CKs, AUXs, and JAs.

Chemicals. Phytohormone standards, i.e., GA1, GA4, GA7, iP, iPR, tZ, tZR, IAA, ABA (2-cis,4-trans-abscisic acid), JA, OPDA (a JA precursor), JA-Ile (a bioactive JA derivative), and stable isotope-labeled compounds (internal standards), i.e., D6ABA ([2H6]-cis,trans-abscisic acid) and D6-iP ([2H6]-N6isopentenyladenine), were purchased from OlChemIm Ltd. (Olomouc, Czech Republic). GA3, IBA, and SA were purchased from Sigma-Aldrich (St. Louis). Double-distilled (MilliQ) water was used throughout the experiment.

Sample preparation. The protocol for phytohormone analysis by high-performance liquid chromatography-electrospray ionizationtandem mass spectrometry (HPLC-ESI-MS/MS) has been adapted from Pan et al. (2010). As plant hormones are unstable at room temperature, phytohormone extraction took place in a cold room at $4^{\circ} \mathrm{C}$, on ice or in liquid nitrogen. Frozen plant tissues were ground in liquid nitrogen with a mortar and a pestle. Each sample was weighed (about $200 \mathrm{mg}$ ) as powder on a microbalance (Denver Instrument, Bohemia, NY, U.S.A.) and was transferred into a 15-ml Falcon tube. Fifty microliters of the working solution of internal standards (500 ppb) and $2 \mathrm{ml}$ of extraction solvent, 2-propanol/ $\mathrm{H}_{2} \mathrm{O} /$ concentrated $\mathrm{HCl}(2: 1: 0.002$, vol $/ \mathrm{vol} / \mathrm{vol})$ were added to each 15-ml tube containing the frozen material. Samples were shaken with a tube rotator (J.A.G. Industries Inc., Baltimore, MD, U.S.A.) at $100 \mathrm{rpm}$ for $30 \mathrm{~min}$ at $4^{\circ} \mathrm{C}$ before adding $1 \mathrm{ml}$ of dichloromethane. Tubes were shaken again for $30 \mathrm{~min}$ in a cold room at $4^{\circ} \mathrm{C}$ and were centrifuged at $4^{\circ} \mathrm{C}$ at $13,000 \times g$ for $5 \mathrm{~min}$. After centrifugation, two phases were formed; plant debris was located between the two layers. About $2 \mathrm{ml}$ of the solvent from the lower phase were transferred and filtered through a $0.2 \mu \mathrm{l}$ syringe filter (Whatman plc, Maidstone, U.K.) into a 2-ml Eppendorf tube. The solvent was evaporated under a gentle nitrogen gas flow; meanwhile, a second extraction was performed by adding $1 \mathrm{ml}$ of dichloromethane to each sample, shaking them for $30 \mathrm{~min}$ in a cold room at $4^{\circ} \mathrm{C}$, and centrifuging them at $4^{\circ} \mathrm{C}$ at $13,000 \times g$ for $5 \mathrm{~min}$. About $1.5 \mathrm{ml}$ of the solvent from the lower phase were transferred and filtered at $0.2 \mu \mathrm{l}$ into the same 2-ml Eppendorf tube. The solvent mixture was concentrated (not completely dry) under a gentle nitrogen gas flow. Samples were then redissolved in $100 \mu \mathrm{l}$ of methanol and were transferred into a $150-\mu \mathrm{l}$ insert in a 2-ml LCMS-certified (liquid chromatography-mass spectrometry) amber glass vials (Waters, Milford, MA, U.S.A.).

HPLC-ESI-MS/MS. Thirty microliters of sample solution were injected twice (for either positive or negative ion mode [Supplementary Table S1]) into a HPLC-ESI-MS/MS for quantification of all phytohormones. The phytohormones were separated by a 
reverse-phase $\mathrm{C}_{18}$ HPLC column (Kinetex $2.6 \mu \mathrm{m} \mathrm{C}_{18} 100 \AA$, LC column $100 \mathrm{~mm} \times 4.6 \mathrm{~mm}$; Phenomenex, Torrance, CA, U.S.A.) on a Waters 2695 HPLC system coupled with a UV detector (Waters 996 photodiode array detector) and a Waters Acquity TQ triple quadrupole mass spectrometer (MS/MS) (Waters TQ Detector, Acquity ultra performance LC), controlled by the Waters Empower 3 Chromatography software. The binary solvent system used for phytohormone separation was $100 \%$ acetonitrile with $0.1 \%$ (vol/vol) formic acid (mobile phase A) and MilliQ water with $0.1(\mathrm{vol} / \mathrm{vol})$ formic acid (mobile phase B) set as follows for a 15 min run: 0 min, $2 \%$ A, $98 \%$ B; 7.27 min, $80 \%$ A, 20\% B; $7.37 \mathrm{~min}, 98 \% \mathrm{~A}, 2 \% \mathrm{~B} ; 10 \mathrm{~min}, 2 \% \mathrm{~A}, 98 \% \mathrm{~B}$. The oven (holding HPLC column) temperature was set at $40^{\circ} \mathrm{C}$ and the solvent flow rate at $0.5 \mathrm{ml} \mathrm{min}{ }^{-1}$. For each phytohormone, the full spectrum of the protonated $[\mathrm{M}+\mathrm{H}]^{+}$or deprotonated $[\mathrm{M}-\mathrm{H}]^{-}$molecular ion and its product ions was generated; the predominant fragmented ion was selected as the product ion for quantification. The ion source in the MS/MS system was ESI operated in the positive or negative ion mode with capillary voltage of $1.5 \mathrm{kV}$. The ionization sources were programmed at $150^{\circ} \mathrm{C}$ and the desolvation temperature was programmed at $450^{\circ} \mathrm{C}$. The MS/MS system was operated in the multiple reaction monitoring (MRM) mode with the optimized collision energy. The ionization energy, MRM transition ions (precursor and product ions), capillary and cone voltage, desolvation gas flow, and collision energy were optimized by the Waters IntelliStart optimization software package. All phytohormone concentrations are presented as nanograms per milligram of fresh weight $(\mathrm{FW})$.

\section{Statistical analysis.}

Three-way MANOVA was used to analyze phytohormonal signature of galls and leaves among all tree genotypes at three collection dates, using SAS (SAS Institute, Cary, NC, U.S.A.). All phytohormone concentrations were used as variables, while tissue (galls versus ungalled control leaves), susceptibility index values (tree genotypes), and Julian days (collection dates) were used as factors. The overall plant response to galling was evaluated using a two-way MANOVA. Differences between galls and their respective ungalled control leaves were used as variables, while susceptibility index values (tree genotypes) and collection dates (Julian days) were used as factors. For both three-way and two-way MANOVAs, we used the Pillai's test statistic, which is considered to be the most robust to violations of assumptions (Scheiner 1993).

GLM procedures were used to analyze phytohormone concentrations in galls and leaves (tissue), among tree genotypes (susceptibility), at three collection dates (Julian days), and interactions between these three factors, using SAS (SAS Institute). GLM were used to examine plant response to galling (difference between galls and their respective ungalled control leaves) for each phytohormone, depending on susceptibility and collection dates, as well as the interaction between these two factors. We used Tukey's HSD as posthoc test (SAS Institute).

To determine the influence of plant genetics, we calculated $\mathrm{H}_{\mathrm{B}}^{2}$ estimates for the constitutive concentration and induced response for each phytohormone phenotype. The constitutive concentration represented the phytohormone concentration in ungalled leaf tissue and the induced response represents the difference in phytohormone concentration between paired samples of galls and their respective ungalled control leaves of each ramet at each sampling date. The genetic contribution of tree genotype was calculated using a mixed linear model with tree genotype as a random effect, ramet location in the common garden was nested within genotype, and sampling date was a fixed experimental effect (Lynch and Walsh 1998). Heritability was calculated as the proportion of variation due to genetic effects and was expressed as $\mathrm{H}^{2}{ }_{\mathrm{B}}=\mathrm{V}_{\mathrm{G}} / \mathrm{V}_{\mathrm{T}}$, where $\mathrm{V}_{\mathrm{G}}$ is the genotypic variance and $\mathrm{V}_{\mathrm{T}}$ is the total variance of the model (Falconer and Mackay 1996). The variance components were estimated using restriction maximum likelihood (REML), and basic confidence intervals $(95 \%)$ of the heritability were calculated using bootstrapping with 10,000 replications. The heritability and bootstrap analyses were conducted with the lme 4 and boot packages in the statistical program $\mathrm{R}$ version 3.5.0 (R Development Core Team 2018; The R Foundation for Statistical Computing, Vienna, Austria).

The level of significance used in all tests was $\alpha=0.05$. All phytohormone concentrations are presented as nanograms per milligram of FW.

\section{ACKNOWLEDGMENTS}

We thank A. Keith for facilitating the sample collection. We also thank two anonymous reviewers for their helpful comments on the manuscript.

\section{LITERATURE CITED}

Adie, B. A., Pérez-Pérez, J., Pérez-Pérez, M. M., Godoy, M., SánchezSerrano, J. J., Schmelz, E. A., and Solano, R. 2007. ABA is an essential signal for plant resistance to pathogens affecting JA biosynthesis and the activation of defenses in Arabidopsis. Plant Cell 19:1665-1681.

Appel, H. M., Fescemyer, H., Ehlting, J., Weston, D., Rehrig, E., Joshi, T., Xu, D., Bohlmann, J., and Schultz, J. 2014. Transcriptional responses of Arabidopsis thaliana to chewing and sucking insect herbivores. Front. Plant Sci. 5:565.

Bailey, J. K., Wooley, S. C., Lindroth, R. L., and Whitham, T. G. 2006. Importance of species interactions to community heritability: A genetic basis to trophic-level interactions. Ecol. Lett. 9:78-85.

Bandurski, R. S., Cohen, J. D., Slovin, J. P., and Reinecke, D. M. 1995. Auxin biosynthesis and metabolism. Pages 39-65 in: Plant hormones: Physiology, biochemistry and molecular biology. P. J. Davies, ed. Kluwer Academic Publishers, Dordrecht, The Netherlands.

Bartlett, L., and Connor, E. F. 2014. Exogenous phytohormones and the induction of plant galls by insects. Arth Plant Inter 8:339-348.

Bedetti, C. S., Modolo, L. V., and Isaias, R. M. S. 2014. The role of phenolics in the control of auxin in galls of Piptadenia gonoacantha (Mart.) MacBr (Fabaceae: Mimosoideae). Biochem. Syst. Ecol. 55: 53-59.

Benková, E., Michniewicz, M., Sauer, M., Teichmann, T., Seifertová, D., Jürgens, G., and Friml, J. 2003. Local, efflux-dependent auxin gradients as a common module for plant organ formation. Cell 115:591-602.

Body, M., Kaiser, W., Dubreuil, G., Casas, J., and Giron, D. 2013. Leafminers co-opt microorganisms to enhance their nutritional environment. J. Chem. Ecol. 39:969-977.

Boivin, S., Fonouni-Farde, C., and Frugier, F. 2016. How auxin and cytokinin phytohormones modulate root microbe interactions. Front. Plant Sci. 7:1240.

Bonfig, K. B., Gabler, A., Simon, U. K., Luschin-Ebengreuth, N., Hatz, M., Berger, S., Muhammad, N., Zeier, J., Sinha, A. K., and Roitsch, T. 2010. Post-translational derepression of invertase activity in source leaves via down-regulation of invertase inhibitor expression is part of the plant defense response. Mol. Plant 3:1037-1048.

Byers, J. A., Brewer, J. W., and Denna, D. W. 1976. Plant growth hormones in pinyon insect galls. Marcellia 39:125-134.

Carneiro, R. G., Oliveira, D. C., and Isaias, R. M. 2014. Developmental anatomy and immunocytochemistry reveal the neo-ontogenesis of the leaf tissues of Psidium myrtoides (Myrtaceae) towards the globoid galls of Nothotrioza myrtoidis (Triozidae). Plant Cell Rep. 33:2093-2106.

Choi, J., Choi, D., Lee, S., Ryu, C. M., and Hwang, I. 2011. Cytokinins and plant immunity: Old foes or new friends? Trends Plant Sci. 16: 388-394.

Compson, Z. G., Larson, K. C., Zinkgraf, M. S., and Whitham, T. G. 2011 A genetic basis for the manipulation of sink-source relationships by the galling aphid Pemphigus batae. Oecologia 167:711-721.

Davies, P. J. 2010. The plant hormones: Their nature, occurrence, and functions. Plant hormones: Biosynthesis, signal transduction, action! P. J. Davies, ed. Kluwer Academic Publishers, Dordrecht, The Netherlands.

Deeken, R., Engelmann, J. C., Efetova, M., Czirjak, T., Müller, T., Kaiser, W. M., Tietz, O., Krischke, M., Mueller, M. J., Palme, K., Dandekar, T., and Hedrich, R. 2006. An integrated view of gene expression and solute 
profiles of Arabidopsis tumors: A genome-wide approach. Plant Cell 18: 3617-3634.

Dickson, L. L., and Whitham, T. G. 1996. Genetically-based plant resistance traits affect arthropods, fungi, and birds. Oecologia 106:400-406.

Donaldson, J. R., Kruger, E. L., and Lindroth, R. L. 2006. Competition- and resource-mediated tradeoffs between growth and defensive chemistry in trembling aspen (Populus tremuloides). New Phytol. 169:561-570.

Dorchin, N., Hoffman, J. H., Stirk, W. A., Novák, O., Strnad, M., and Van Staden, J. 2009. Sexually dimorphic structures correspond to differential phytohormone contents in male and female larvae of a pteromalid wasp. Phytol Entomol 34:359-369.

Erb, M., Meldau, S., and Howe, G. A. 2012. Role of phytohormones in insect-specific plant reactions. Trends Plant Sci. 17:250-259.

Falconer, D. S., and Mackay, T. F. C. 1996. Introduction to quantitative genetics, 4th Ed. Pearson, Prentice Hall, Saddle River, NJ, U.S.A.

Giron, D., Frago, E., Glevarec, G., Pieterse, C. M. J., and Dicke, M. 2013. Cytokinins as key regulators in plant-microbe-insect interactions: Connecting plant growth and defence. Funct. Ecol. 27:599-609.

Giron, D., Huguet, E., Stone, G. N., and Body, M. 2016. Insect-induced effects on plants and possible effectors used by galling and leaf-mining insects to manipulate their host-plant. J. Insect Physiol. 84:70-89.

Gohlke, J., and Deeken, R. 2014. Plant responses to Agrobacterium tumefaciens and crown gall development. Front. Plant Sci. 5:155.

Greenboim-Wainberg, Y., Maymon, I., Borochov, R., Alvarez, J., Olszewski, N., Ori, N., Eshed, Y., and Weiss, D. 2005. Cross talk between gibberellin and cytokinin: The Arabidopsis GA response inhibitor SPINDLY plays a positive role in cytokinin signaling. Plant Cell 17:92-102

Harper, A. M. 1959. Gall aphids on poplar in Alberta. I. Descriptions of galls and distributions of aphids. Can. Entomol. 91:489-496.

Heinrich, M., Hettenhausen, C., Lange, T., Wünsche, H., Fang, J., Baldwin, I. T., and $\mathrm{Wu}$, J. 2013. High levels of jasmonic acid antagonize the biosynthesis of gibberellins and inhibit the growth of Nicotiana attenuata stems. Plant J. 73:591-606.

Holub, J., Hanuš, J., Hanke, D. E., and Strnad, M. 1998. Biological activity of cytokinins derived from ortho- and meta-hydroxybenzyladenine. Plant Growth Regul. 26:109-115.

Hori, K. 1992. Insect secretions and their effect on plant growth, with special reference to Hemipterans. Pages 157-170 in: Biology of insect induced galls. Shorthouse, J. D., and Rohfritsch, O., eds. Oxford University Press, New York.

Huot, B., Yao, J., Montgomery, B. L., and He, S. Y. 2014. Growth-defense tradeoffs in plants: A balancing act to optimize fitness. Mol. Plant 7: 1267-1287.

Hwang, S. Y., and Lindroth, R. L. 1997. Clonal variation in foliar chemistry of aspen: Effects on gypsy moths and forest tent caterpillars. Oecologia 111:99-108

Iqbal, N., Nazar, R., Khan, M. I., Masood, A., and Khan, N. A. 2011. Role of gibberellins in regulation of source-sink relations under optimal and limiting environmental conditions. Curr. Sci. 10:998-1007.

Jones, R. L., and Kaufman, P. B. 1983. The role of gibberellins in plant cell elongation. Crit. Rev. Plant Sci. 1:23-47.

Kearsley, M. J., and Whitham, T. G. 1989. Developmental changes in resistance to herbivory: Implications for individuals and populations. Ecol 70:422-434.

Keith, A. R., Bailey, J. K., and Whitham, T. G. 2010. A genetic basis to community repeatability and stability. Ecology 91:3398-3406.

Keith, A. R., Bailey, J. K., Lau, M. K., and Whitham, T. G. 2017. Geneticsbased interactions of foundation species affect community diversity, stability, and network structure. P. Roy. Soc. B-Biol. Sci. 284:20162703.

Larson, K. C., and Whitham, T. G. 1991. Manipulation of food resources by a gall-forming aphid: The physiology of sink-source interactions. Oecologia 88:15-21.

Larson, K. C., and Whitham, T. G. 1997. Competition between gall aphids and natural plant sinks: Plant architecture affects resistance to galling. Oecologia 109:575-582.

Li, X. Q., Liu, Y. Z., Guo, W. F., Solanki, M. K., Yang, Z. D., Xiang, Y., Ma, Z. C., and Wen, Y. G. 2017. The gall wasp Leptocybe invasa (Hymenoptera: Eulophidae) stimulates different chemical and phytohormone responses in two Eucalyptus varieties that vary in susceptibility to galling. Tree Physiol. 37:1208-1217.

Liscum, E., Askinosie, S. K., Leuchtman, D. L., Morrow, J., Willenburg, K. T., and Coats, D. R. 2014. Phototropism: Growing towards an understanding of plant movement. Plant Cell 26:38-55.

Lynch, M., and Walsh, B. 1998. Genetics and Analysis of Quantitative Traits. Sinauer, Sunderland, MA, U.S.A.

Mani, M. S. 1964. Ecology of Plant Galls. W. Junk, ed. The Hague.

Mapes, C. C., and Davies, P. J. 2001a. Indole-3-acetic acid and ball gall development on Solidago altissima. New Phytol. 151:195-202.
Mapes, C. C., and Davies, P. J. 2001b. Cytokinins in the ball gall of Solidego altissima and in the gall forming larvae of Eurosta solidaginis. New Phytol. 151:203-212.

Moosavi, M. R. 2017. The effect of gibberellin and abscisic acid on plant defense responses and on disease severity caused by Meloidogyne javanica on tomato plants. J. Gen. Plant Pathol. 83:173-184.

Morkunas, I., and Gabryś, B. 2011. Phytohormonal signaling in plant responses to aphid feeding. Acta Physiol. Plant. 33:2057-2073.

Naseem, M., Kaltdorf, M., and Dandekar, T. 2015. The nexus between growth and defence signalling: Auxin and cytokinin modulate plant immune response pathways. J. Exp. Bot. 66:4885-4896.

Noriega, X., and Pérez, F. J. 2017. ABA biosynthesis genes are downregulated while auxin and cytokinin biosynthesis genes are up-regulated during the release of grapevine buds from endodormancy. J. Plant Growth Regul. 36:814-823.

Pan, X., Welti, R., and Wang, X. 2010. Quantitative analysis of major plant hormones in crude plant extracts by high-performance liquid chromatography-mass spectrometry. Nat. Protoc. 5:986-992.

Pieterse, C. M., Van der Does, D., Zamioudis, C., Leon-Reyes, A., and Van Wees, S. C. 2012. Hormonal modulation of plant immunity. Annu. Rev. Cell Dev. Biol. 28:489-521.

Price, P. W., Waring, G. L., and Fernandes, G. W. 1987. Adaptive nature of insect galls. Environ. Entomol. 16:15-24.

Raman, A., Schaefer, C. W., and Withers, T. M. 2005. Galls and gallinducing arthropods: An overview of their biology, ecology and evolution. Pages 1-33 in: Biology, Ecology, and Evolution of GallInducing Arthropods. A. Raman, C. W. Schaefer, and T. M. Withers, eds. Science Publishers, Enfield

Rehill, B. J., and Schultz, J. C. 2003. Enhanced invertase activities in the galls of Hormaphis hamamelidis. J. Chem. Ecol. 29:2703-2720.

Richardson, R. A., Body, M., Warmund, M. R., Schultz, J. C., and Appel, H. M. 2017. Morphometric analysis of young petiole galls on the narrowleaf cottonwood, Populus angustifolia, by the sugarbeet root aphid, Pemphigus betae. Protoplasma 254:203-216.

Robert-Seilaniantz, A., Grant, M., and Jones, J. D. 2011. Hormone crosstalk in plant disease and defense: More than just jasmonate-salicylate antagonism. Annu. Rev. Phytopathol. 49:317-343.

Rohfritsch, O. 1992. Patterns in gall development. Pages 60-86 in: Biology of Insect Induced Galls. Shorthouse, J. D., and Rohfritsch, O., eds. Oxford University Press, New York.

Roitsch, T., and Ehneß, R. 2000. Regulation of source/sink relations by cytokinins. Plant Growth Regul. 32:359-367.

Roitsch, T., and González, M. C. 2004. Function and regulation of plant invertases: Sweet sensations. Trends Plant Sci. 9:606-613.

Scheiner, S. M. 1993. MANOVA: Multiple response variables and multispecies interactions. Pages 94-112 in: Design and Analysis of Ecological Experiments. Scheiner, M., and Gurevitch, J., eds. Chapman and Hall, New York, New York.

Schweitzer, J. A., Bailey, J. K., Hart, S. C., Wimp, G. M., Chapman, S. K., and Whitham, T. G. 2005. The interaction of plant genotype and herbivory decelerate leaf litter decomposition and alter nutrient dynamics. Oikos 110:133-145.

Seo, M., Hanada, A., Kuwahara, A., Endo, A., Okamoto, M., Yamauchi, Y., North, H., Marion-Poll, A., Sun, T. P., Koshiba, T., Kamiya, Y., Yamaguchi, S., and Nambara, E. 2006. Regulation of hormone metabolism in Arabidopsis seeds: Phytochrome regulation of abscisic acid metabolism and abscisic acid regulation of gibberellin metabolism. Plant J. 48:354-366.

Shorthouse, J. D., Wool, D., and Raman, A. 2005. Gall-inducing insects-Nature's most sophisticated herbivores. Basic Appl. Ecol. 6:407-411

Smith, D. S., Bailey, J. K., Shuster, S. M., and Whitham, T. G. 2011. A geographic mosaic of trophic interactions and selection: Trees, aphids and birds. J. Evol. Biol. 24:422-429.

Stes, E., Vandeputte, O. M., El Jaziri, M., Holsters, M., and Vereecke, D. 2011. A successful bacterial coup d'état: How Rhodococcus fascians redirects plant development. Annu. Rev. Phytopathol. 49:69-86.

Stintzi, A., Weber, H., Reymond, P., Browse, J., and Farmer, E. E. 2001 Plant defense in the absence of jasmonic acid: The role of cyclopentenones. Proc. Natl. Acad. Sci. U.S.A. 98:12837-12842.

Stone, G. N., and Schönrogge, K. 2003. The adaptive significance of insect gall morphology. Trends Ecol. Evol. 18:512-522.

Straka, J. R., Hayward, A. R., and Emery, R. J. N. 2010. Gall-inducing Pachypsylla celtidis (Psyllidae) infiltrate hackberry trees with high concentrations of phytohormones. J. Plant Interact. 5:197-203.

Suzuki, H., Yokokura, J., Ito, T., Arai, R., Yokoyama, C., Toshima, H., Nagata, S., Asami, T., and Suzuki, Y. 2014. Biosynthetic pathway of the phytohormone auxin in insects and screening of its inhibitors. Insect Biochem. Mol. Biol. 53:66-72. 
Tanaka, Y., Okada, K., Asami, T., and Suzuki, Y. 2013. Phytohormones in Japanese mugwort gall induction by a gall-inducing gall midge. Biosci. Biotechnol. Biochem. 77:1942-1948.

Thaler, J. S., Humphrey, P. T., and Whiteman, N. K. 2012. Evolution of jasmonate and salicylate signal crosstalk. Trends Plant Sci. 17:260-270.

Tokuda, M., Jikumaru, Y., Matsukura, K., Takebayashi, Y., Kumashiro, S., Matsumura, M., and Kamiya, Y. 2013. Phytohormones related to host plant manipulation by a gall-inducing leafhopper. PLoS One 8:e62350.

Tooker, J. F., and De Moraes, C. M. 2009. A gall-inducing caterpillar species increases essential fatty acid content of its host plant without concomitant increases in phytohormone levels. Mol. Plant-Microbe Interact. 22:551-559.

Tooker, J. F., and De Moraes, C. M. 2011. Feeding by a gall-inducing caterpillar species alters levels of indole-3-acetic and abscisic acid in Solidago altissima (Asteraceae) stems. Arth Plant Int 5:115-124.

Tooker, J. F., and Helms, A. M. 2014. Phytohormone dynamics associated with gall insects, and their potential role in the evolution of the gallinducing habit. J. Chem. Ecol. 40:742-753.

USDA-NRCS. 2008. Plant guide: Narrowleaf cottonwood Populus angustifolia James. United States Department of Agriculture-Natural Resources Conservation Services, Washington, D.C. https://plants.usda. gov/plantguide/pdf/cs_poan3.pdf.

Vidhyasekaran, P. 2015. Gibberellin Signaling in Plant Innate Immunity. Pages 383-401 in: Plant Hormone Signaling Systems in Plant Innate Immunity. P. Vidhyasekaran, ed. Springer, Dordrecht.

Whitham, T. G. 1983. Host manipulation of parasites: Within-plant variation as a defense against rapidly evolving pests. Pages 15-41 in: Variable Plants and Herbivores in Natural and Managed Systems. R. Denno, and M. S. McClure, eds. Academic Press, New York.

Whitham, T. G. 1989. Plant hybrid zones as sinks for pests. Science 244:1490-1493.
Whitham, T. G., Bailey, J. K., Schweitzer, J. A., Shuster, S. M., Bangert, R. K., LeRoy, C. J., Lonsdorf, E. V., Allan, G. J., DiFazio, S. P., Potts, B. M., Fischer, D. G., Gehring, C. A., Lindroth, R. L., Marks, J. C., Hart S. C., Wimp, G. M., and Wooley, S. C. 2006. A framework for community and ecosystem genetics: From genes to ecosystems. Nat. Rev. Genet. 7:510-523.

Whitham, T. G., Difazio, S. P., Schweitzer, J. A., Shuster, S. M., Allan, G. J., Bailey, J. K., and Woolbright, S. A. 2008. Extending genomics to natural communities and ecosystems. Science 320:492-495.

Wood, B. W., and Payne, J. A. 1988. Growth regulators in chestnut shoot galls infected with oriental chestnut gall wasp, Dryocosmus kuriphilus (Hymenoptera: Cynipidae). Environ. Entomol. 17:915-920.

Yamaguchi, H., Tanaka, H., Hasegawa, M., Tokuda, M., Asami, T., and Suzuki, Y. 2012. Phytohormones and willow gall induction by a gallinducing sawfly. New Phytol. 196:586-595.

Zhang, H., Guiguet, A., Dubreuil, G., Kisiala, A., Andreas, P., Emery, R. J. N., Huguet, E., Body, M., and Giron, D. 2017. Dynamics and origin of cytokinins involved in plant manipulation by a leaf-mining insect. Insect Sci. 24:1065-1078.

Zhang, P. J., Zheng, S. J., van Loon, J. J., Boland, W., David, A., Mumm, R., and Dicke, M. 2009. Whiteflies interfere with indirect plant defense against spider mites in lima bean. Proc. Natl. Acad. Sci. U.S.A. 106: 21202-21207.

Zinkgraf, M. S., Meneses, N., Whitham, T. G., and Allan, G. J. 2016. Genetic variation in NIN1 and C/VIF1 genes is significantly associated with Populus angustifolia resistance to a galling herbivore, Pemphigus betae. J. Insect Physiol. 84:50-59.

Zürcher, E., and Müller, B. 2016. Cytokinin synthesis, signaling, and function-Advances and new insights. Int. Rev. Cell Mol. Biol. 324:1-38. 